\title{
UN CONJUNTO DE MATERIALES DE LA SERRETA DE ALCOY
}

\author{
LORENZO ABAD CASAL \\ Universidad de Alicante
}

\begin{abstract}
El estudio de una phiale mesomphala de Cales en el Museo Arqueológico de Alcoy nos ha permitido la identificación de un conjunto de materiales de finales del siglo III a.C., compuesto por cerámica de Cales, de barniz negro e ibérica, y diversos objetos de metal, hueso y terracota. Todo ello se encontró en un departamento de La Serreta de Alcoy. Se hacen, además, algunas reflexiones sobre la presencia en la Península Ibérica de las cerámicas de barniz negro. La decoración de esta última, a base de erotes entre plantas, y su asociación con un vasito caliciforme, permite plantear asimismo determinados problemas acerca de su significado y de la recepción y asimilación, por los iberos, de modelos extrapeninsulares.
\end{abstract}

The study of a phiale mesomphala from Cales in the Archaelogical Museum at Alcoy, has allowed us the identification of a series of pieces dated at the end of the III century b.C., which were discovered in a room at the Iberian village of La Serreta ( $\mathrm{Al}$ coy): black plain, Iberian and Calenian pottery, objects of metal, bone and terracota. We have made some reflections about the imported pottery, specially the Calenian pottery. Its decoration, Eroten among flowers, and its association with a calyx-cup, makes it possible to outline some of the problems about the reception and assimilation of $\mathrm{He}$ llenistic models between the Iberians.

El Museo de Alcoy conserva entre las cerámicas de barniz negro procedentes del yacimiento de La Serreta una pátera con relieves de tipo caleno. Su interés es grande, en primer lugar porque se trata de un tipo de cerámica poco frecuente en la Península Ibérica (GARCIA Y BELLIDO, 1952, 389 ss; DOMERGUE, 1969, 159 ss; BELTRAN LLORIS, 1975, $59 \mathrm{ss}$ ), y en segundo lugar porque procede de uno de los principales yacimientos ibéricos de la zona, que ha sido objeto de varias campañas de excavación, pero que aún permanece prácticamente inédito. El interés de esta pieza aumentó aún más cuando pudimos encontrar, entre los papeles de don Camilo Visedo Moltó, antiguo director de las excavaciones, el diario correspondiente al mes de mayo de 1953; en él daba cumplida cuenta de cuándo y dónde había aparecido, así como de los materiales que la acompañaban. El estudio de todo este conjunto permite, por primera vez, conocer el ajuar de un departamento de este yacimiento. Ello no hubiera podido realizarse sin contar con la ayuda y colaboración, en todo momento, del doctor don Federico Rubio Gomis, director del Museo de Alcoy, y de don José María Segura Martí, conservador del mismo, a quienes queremos expresar desde aquí nuestro agradecimiento. Igualmente a mi alumna María Dolores Sánchez de Prado, autora de varios de los dibujos, y a don Emilio Cortell Pérez, que es coautor de la figura número 2. Las sugerencias de los doctores Miguel A. Elvira, Ricardo Olmos y J. Pérez Ballester, contribuyeron asimismo a mejorar sustancialmente el estudio de la cerámica de barniz negro. 


\section{EI yacimiento}

La Serreta es un poblado ibérico situado en las proximidades de la ciudad de Alcoy, en la parte más elevada de la cadena montañosa del mismo nombre. Desde 1920 se han venido realizando excavaciones arqueológicas de manera discontinua, a cargo de C. Visedo, V. Pascual y M. Tarradell, pero hasta el momento los resultados obtenidos no se han recogido en ninguna publicación. Lo puesto al descubierto correponde a parte de un poblado de estructura geomórfica, con casas de dos departamentos y paredes de mampostería, y un santuario del que no se conserva estructura alguna. Los materiales definitorios de su cronología son las cerámicas áticas de figuras rojas y barniz negro, campanienses A y B y una gran cantidad de cerámicas ibéricas de las que sobresalen algunos ejemplares decorados con figuras del estilo de Oliva-Liria. De todo ello puede deducirse una cronología entre los siglos IV y II AC, sin alcanzar la romanización. Para el santuario, en cambio, numerosas monedas romanas y cerámicas sigilatas, así como la ausencia de campaniense, indican una cronología de época imperial. No parece, por tanto, que coexistieran poblado y santuario.

Algunas indicaciones de los excavadores parecen presuponer la existencia de al menos dos niveles en el yacimiento ibérico, uno correspondiente al siglo IV y quizás a parte del III, y otro al III y parte del II AC (TARRADELL, 1970, 481 ss). La descripción más detallada del yacimiento puede verse en Llobregat, 1972, 55 ss, y Aranegui, 1970, 107 ss.

\section{La excavación de mayo de 1953}

En el Registro General del Museo de Alcoy consta que la mayor parte de la pátera ingresó el día 19 de mayo de 1953, pero queda claro que debía formar parte de un lote de materiales cuya incorporación al Museo se hizo de forma paulatina, ya que un fragmento del mismo plato ingresó, junto con otros objetos, el día 26 de mayo. Como conocíamos la costumbre de don Camilo Visedo de ingresar las piezas en el Museo muy pocos días después de hallarlas en la excavación, supusimos que todo el conjunto debía corresponder a una misma campaña de excavación, y posiblemente a un área muy determinada.

Estas sospechas se confirmaron cuando pudimos localizar, en el mismo Museo de Alcoy, el diario de excavación correspondiente a estas fechas. De él se conservan dos versiones; la primera corresponde a las notas que el autor tomó durante los trabajos de campo, y la segunda a su puesta en limpio. Ambas difieren sólo en detalles, excepto en lo que corresponde al día 25.

A continuación transcribiremos la parte del diario correspondiente a la campaña de excavación en que apareció la pátera de que estamos tratando. La transcripción es textual, sin más añadido que el número de orden que incluimos entre paréntesis para facilitar posteriores referencias.

\section{Año 1953}

El día 10 de mayo se empezó la campaña en La Serreta, siguiendo en el mismo sitio anterior. Se puso al descubierto una pared de 3,50 metros de largo por 0,45 metros de ancho, la cual delimitaba un compartimiento de viviendas teniendo la roca por pared del fondo. Salió en la parte superior mucha piedra desprendida de arriba y al final una capa arcillosa, con (1) barros sueltos, algunos pintados, y restos de carbón. La profundidad alcanzó un metro y medio desde la superficie.

Día 14. Se siguió limpiando el departamento anterior, (2) con sólo algún barro suelto. 
Día 17. Salieron los siguientes objetos: (3) Plato incompleto con grabados interesantes, color negro mate; (4) Un plomo de forma circular sin escritura; (5) Dos vasitos pequeños y un platito; (6) Tres fusaiolas de varias formas; (7) Una cuenta de collar globular de barro; (8) Una afiladora de piedra negra con agujero al extremo; (9) Una piedra pulida silícea; (10) Una piedra con agujero intencionado; (11) Un punzón de hueso incompleto; (12) Una cucharilla de bronce y otro utensilio indeterminado; (13) Barros de grandes recipientes destrozados; (14) Un hierro que parece espuela.

Día 24. Siguió la excavación en el mismo sitio, saliendo lo siguiente: (15) Un punzón de hueso que le falta la punta; (16) Un barro perteneciente al plato último grabado en negro; (17) Una arenisca para afilar; (18) Un hueso aserrado con intención; (19) Un vasito incompleto y algún barro pintado.

Día 25. (20) Sólo salió parte del pie del plato con relieve. (En la versión original se leía lo siguiente: «Sólo salió una pequeña cazolita de cerámica campaniana que mide de altura 228 milímetros por 135 de diámetro, la cual es parte del plato con relieves»).

Día 4 de junio. (21) Una bolita de plomo con agujero y algunos barros; (22) La mitad de una moledera de 0,55 metros de diámetro.

Día 7 de junio. (23) Cuatro hierros en mal estado; (24) Un platito cerámico; (25) Un fusaiolo troncocónico y un diente de cáprido.

Día 14 de junio. (26) Sólo un platito incompleto y bocas de grandes vasos. El departamento acusa la misma disposición que los anteriores, con la siguiente forma (fig. 1).

Día 6 de julio. (27) Se encontró un hacha de diorita en perfecto estado de conservación y varios hierros en mal estado.

Día 7. (28) Barros sueltos y una piedra lávica.

Día 8. (29) Trozo de plomo de bastante peso sin poder determinar su uso por su mal estado.

Día 9. (30) Un plato de cerámica campaniana que le falta sobre una mitad.

Día 10. Al terminar en este sitio, se pasó a otra zona más baja, con igual disposición de departamentos sobre roca de fondo. Empezó a salir mucha cerámica destrozada de imposible reconstrucción y un clavo de hierro.
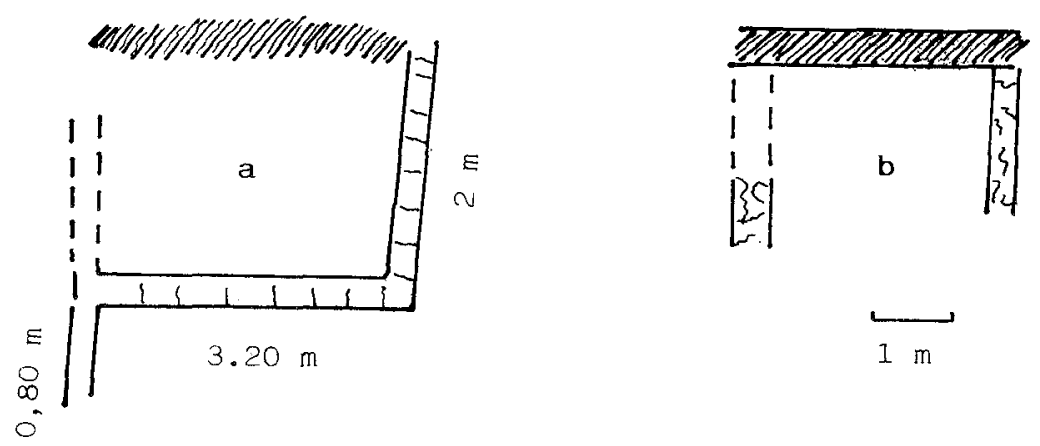

Fig. 1. Croquis del departamento excavado; a, según la primera redacción del diario de C. Visedo; b, según la segunda. 


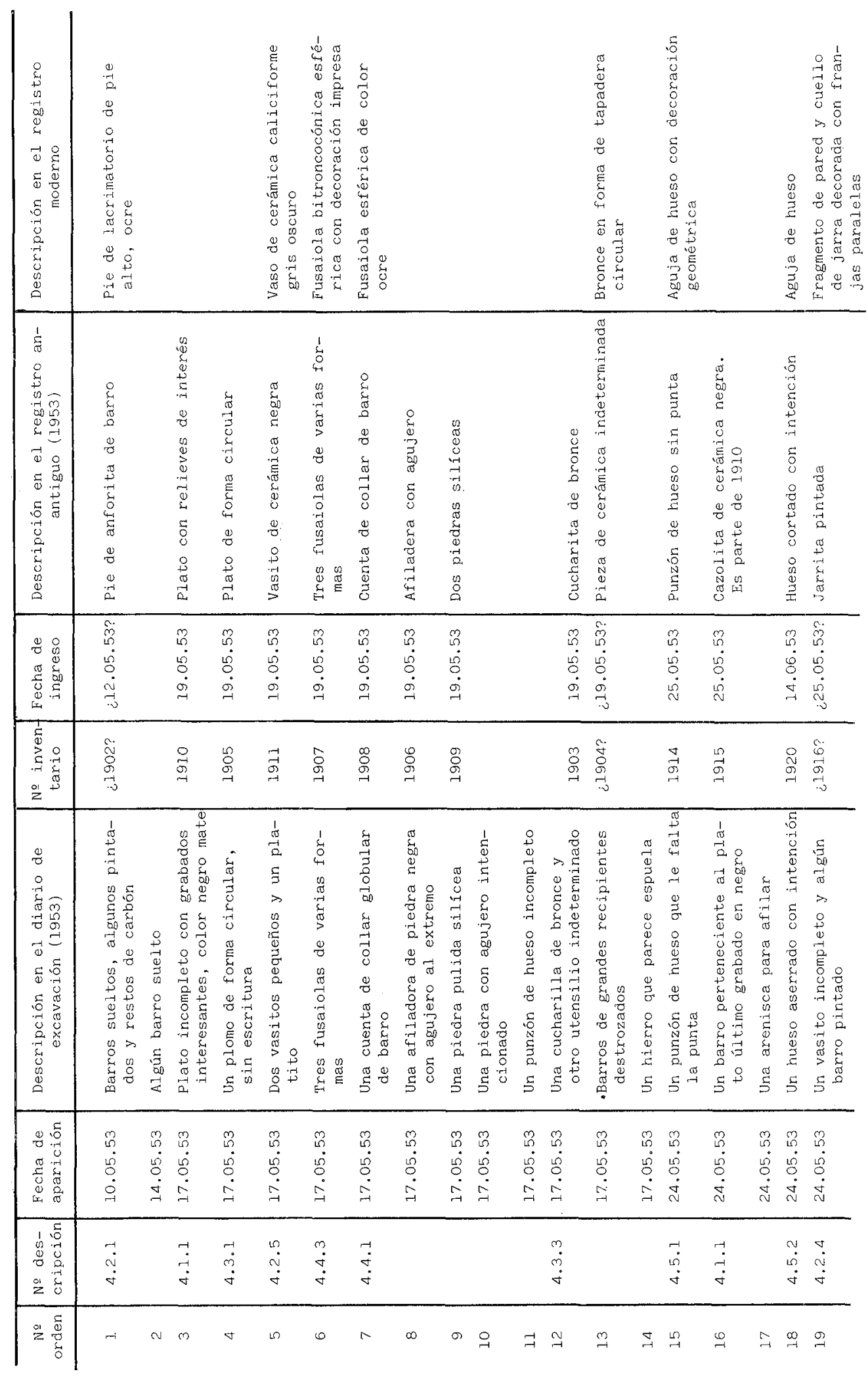




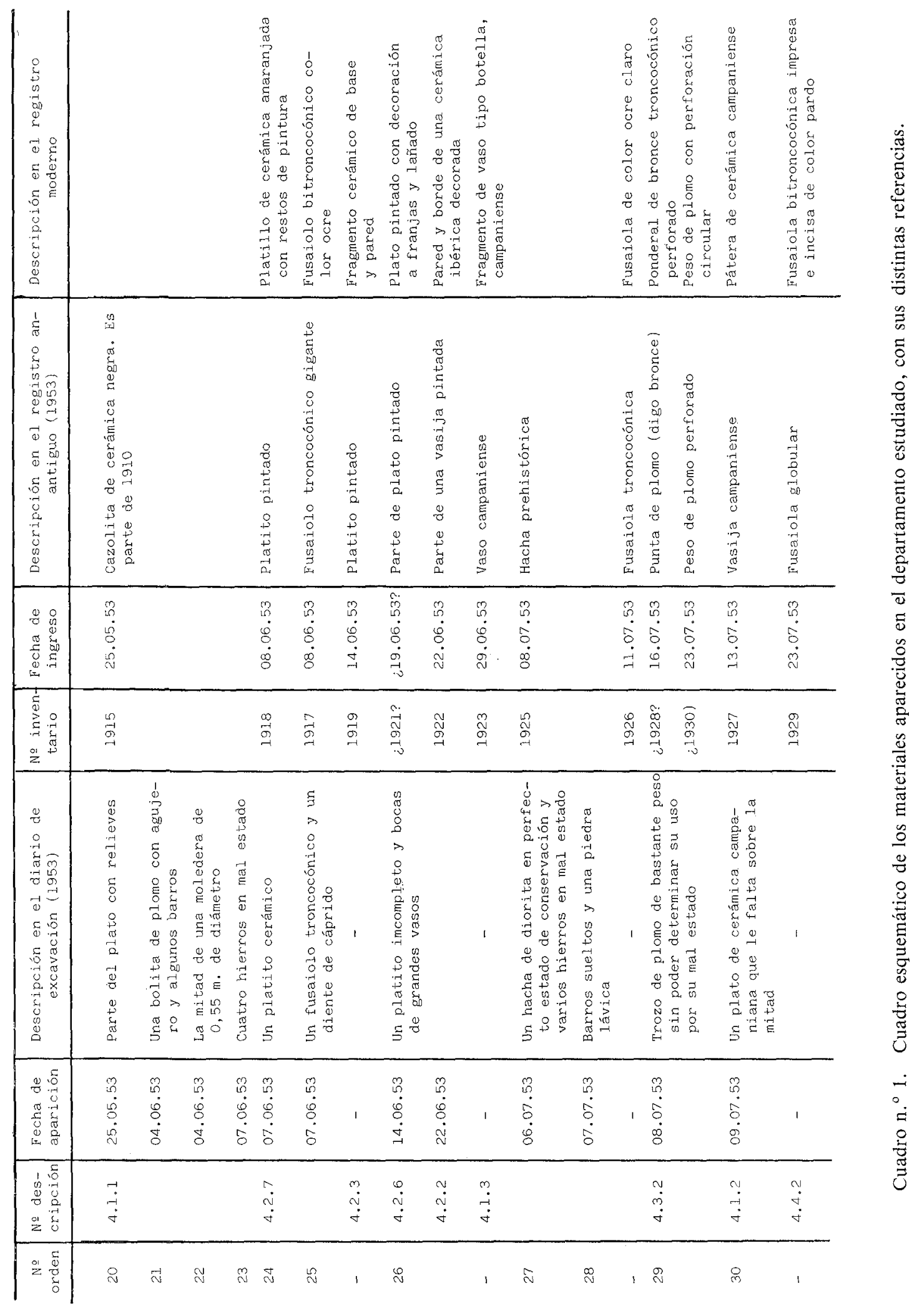


Cotejando estas notas con el registro general del Museo, encontramos que los objetos ingresados entre los días 12 de mayo y 24 de julio coinciden en buena parte con los descritos en el diario del excavador, como puede observarse en el cuadro número 1 , donde se colacionan las fechas de descubrimiento y de ingreso, el número de inventario y las diferentes descripciones de cada una de las piezas.

Si examinamos el calendario de 1953, observaremos que las fechas de excavación de los meses de mayo y junio coinciden por regla general con domingos y días festivos, en tanto los de ingreso de material suelen ser los lunes o martes siguientes. En la segunda quincena de junio, sin embargo, no se excava ningún día y, en cambio, hay varios con ingresos, correspondientes, tal vez, a piezas acumuladas durante los anteriores días de excavación y no ingresadas. Algo parecido ocurre con el mes de julio, ya que la excavación tiene lugar entre los días 6 y 10 y los ingresos, en cambio, se prolongan hasta el 23.

Como toda la parte transcrita del diario se refiere a la excavación de un solo departamento, y los materiales descubiertos en él coinciden en buena parte con los ingresados en el museo por las mismas fechas, parece lógico deducir que todos los inventariados entre los números 1.902 y 1.930 corresponden al ajuar del departamento citado y que, por tanto, constituyen el contexto de la pátera de barniz negro que ha sido el origen de este estudio.

Hay que indicar, no obstante, que algunas piezas recogidas en el inventario del Museo no figuran expresamente en el diario de excavación. Así la número 1.922, que podría incluirse tal vez en cualquiera de los apartados anteriores que hacen referencia a la aparición de «barros pintados», o la número 1.923 , cerámica de barniz negro cuya aparición solía hacer constar siempre el excavador. El número 1.924 corresponde a un «cuenco prehistórico» procedente del yacimiento de La Mola Alta de Serelles.

\section{El departamento excavado}

C. Visedo acompaña su descripción con un croquis muy somero del departamento en que se encontraron los objetos (fig. 1). Se trata de una estancia rectangular con uno de sus lados tallado en la roca virgen y los tres restantes cerrados por muros de piedra. Unos de los muros cortos, en el que parece abrirse una puerta, aparece punteado, por lo que pudiera tratarse de una reconstrucción ideal. En el croquis, el departamento se encuentra aislado, por lo que no puede identificarse en ninguno de los planos generales conocidos de La Serreta.

En el diario se indica que el departamento excavado dio una potencia de 1,50 metros, pero no se recoge dato alguno que nos permita la reconstrucción de su posible estratigrafía. Un intento realizado a base de agrupar los materiales descubiertos en los primeros días, que debían ser los más modernos, y en los días subsiguientes, que serían tanto más antiguos cuanto más profundos, no ha proporcionado resultados concluyentes.

\section{El material descubierto}

Se compone básicamente de cerámica de barniz negro e ibérica, objetos metálicos y algunas piedras de varios usos.

\subsection{La cerámica de barniz negro}

4.1.1. (N. ${ }^{\circ}$ de orden 3,16 y $20 ;$ n. $^{\circ}$ de inventario 1.910 y 1915; fig. 2). Varios fragmentos de una patera umbilicata del tipo denominado caleno, de pasta ocre, bien levigada y borde ligeramente engrosado. Barniz negro espeso bien repartido por la superficie. Su centro está ocupado, como es normal en este tipo de cerámica, por un umbi- 
licus de forma aproximadamente semiesférica, con un ligero estrangulamiento en la zona de contacto con el fondo interior. Toda la superficie interna está decorada con relieves hechos a molde, con la siguiente sucesión desde dentro hacia fuera: un trazo fino, una línea de postas bastante irregular con puntos bajo ellas; otro trazo más ancho con una línea de puntos en su cara exterior; un friso de relieves formado por grupos de dos plantas afrontadas muy estilizadas, con varias ramas que terminan en hojas acorazonadas, capullos florales sin abrir y flores multipétalas; posiblemente se trate de adormideras. Entre las ramas, y justo sobre el lugar de donde arrancan, vuelan erotes que sostienen en sus manos una corona formada por una hilera de puntos. La actitud de los erotes, con los brazos extendidos, sólo un ala visible y las piernas ligeramente encogidas, es la misma en todos ellos. Sobre la línea de puntos inferior, un pájaro sirve de solución de continuidad entre los diversos grupos. Lo conservado - algo menos de la mitad del plato- está hecho a base de punzones muy parecidos, aunque no idénticos, que confieren una gran uniformidad a la decoración. La irregularidad de ésta obliga a pensar o que el molde no era de gran calidad o que los punzones o el propio molde habían sufrido ya un considerable proceso de desgaste cuando se fabricó la pátera de Alcoy.

4.1.2. (N. ${ }^{\circ}$ de orden $30 ; n .^{\circ}$ de inventario 1.927 ; fig. 3a). Fragmento de una pátera o cuenco de forma Lamboglia 25 , de pasta rojiza, barniz negro con reflejo metálico desaparecido en varios lugares y estrías de torneado en su parte exterior, sobre todo en la mitad superior. Pasta ligeramente granulosa, con desgrasantes calizos y vacuolas. Fondo exterior y superficie de apoyo del pie sin barnizar. En la zona de unión de la pared externa con el pie, falta el barniz en cinco lugares; su espacio está ocupado por una mancha rojiza, en ocasiones con punto central y ribetes negros. El fondo externo está cubierto parcialmente por un derrame de barniz que le da un tono rojizo.

4.1.3. (N. ${ }^{\circ}$ de orden -; n. ${ }^{\circ}$ de inventario 1923; fig. 3b). Fragmento de cerámica de barniz negro de difícil identificación. Su cuerpo, de forma ligeramente elipsoidal, está decorado con estrías horizontales. En su parte superior se conserva parte del hombro, troncocónico, que debía enlazar el cuerpo con un cuello completamente perdido. Ello viene apoyado por el hecho de que en la zona fragmentada del hombro parece apreciarse una irregularidad que puede corresponder al arranque de un asa de implantación vertical. Pasta de color ocre, amplias superficies de tonos grisáceos y, sobre todo, amarronados. En la zona de contacto con el pie, amplias manchas rojizas. Parece que tanto el fondo externo como la superficie de reposo estuvieron barnizados, aunque ambos han perdido casi todo el barniz. El interior no lo estuvo, como corresponde a una forma cerrada.

\subsection{Cerámica ibérica}

Constituye el lote más numeroso de objetos, y agrupa restos de ocho recipientes, en su mayor parte bastante fragmentados. Unos conservan pinturas, otros la han perdido totalmente o no la tuvieron nunca.

4.2.1. (N. ${ }^{\circ}$ de orden $1 ; n .^{\circ}$ de inventario 1.902; fig. 3c). Pie de ungüentario fusiforme con base engrosada en forma de moldura troncocónica o semicircular, ya que la rotura no permite apreciarlo con exactitud. Pasta de color ocre en su tercio externo y gris en los dos tercios restantes. La superficie exterior es también de color ocre y la interior, en cambio, negro, aunque en algunos lugares donde este barniz se ha desprendido aparece por debajo una finísima capa de color ocre. La rotura del recipiente deja ver solamente el arranque de uno de sus lados, aunque lo que se conserva es suficiente para observar estrías de torneado en su fondo interno.

4.2.2. (N. ${ }^{\circ}$ de orden $26 ; n .^{\circ}$ de inventario 1.922; fig. $3 \mathrm{~d}$ ). Parte superior de una gran vasija ibérica de cuerpo de tendencia globular, cuello apenas indicado y ancho borde 


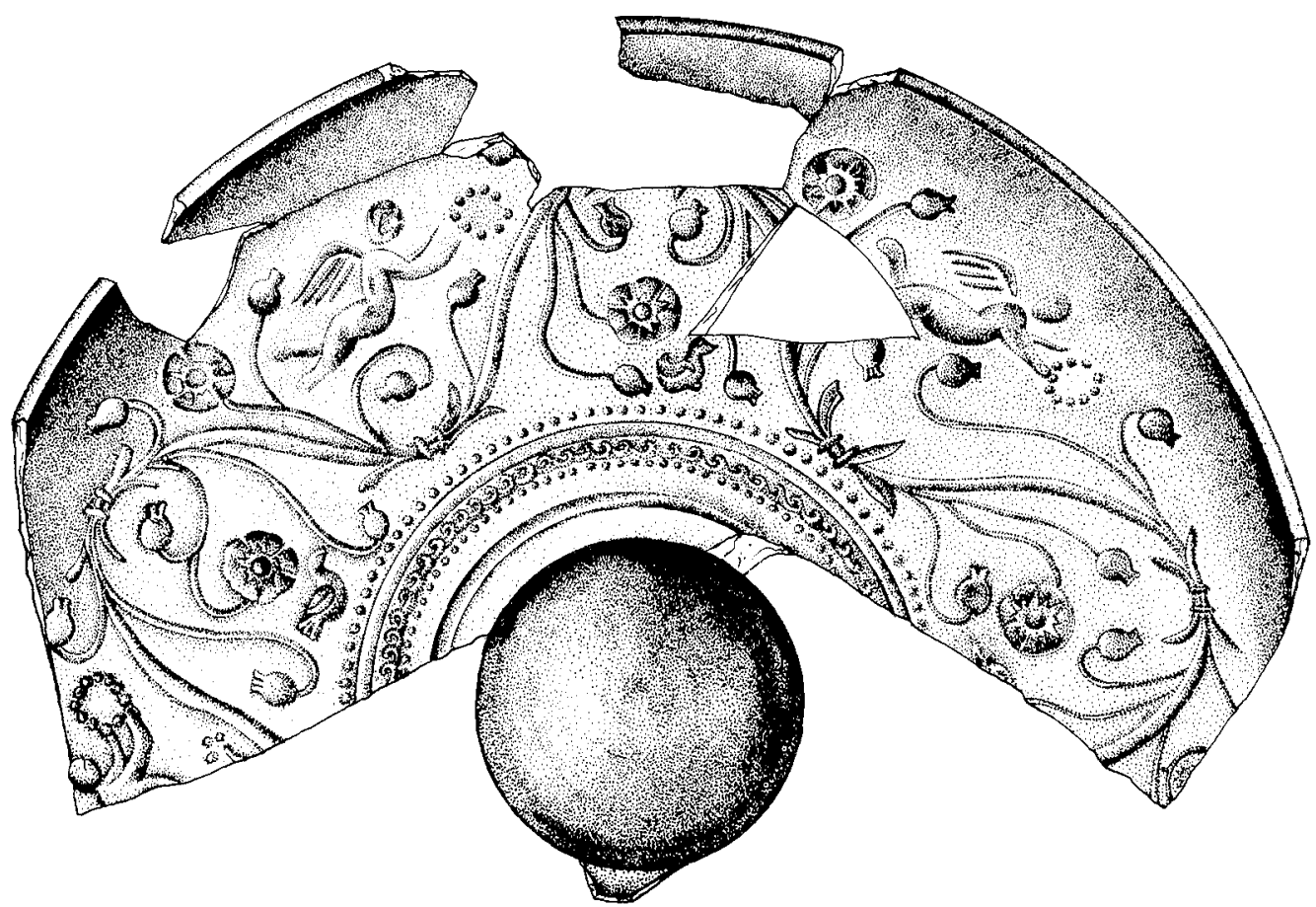

4.1 .1
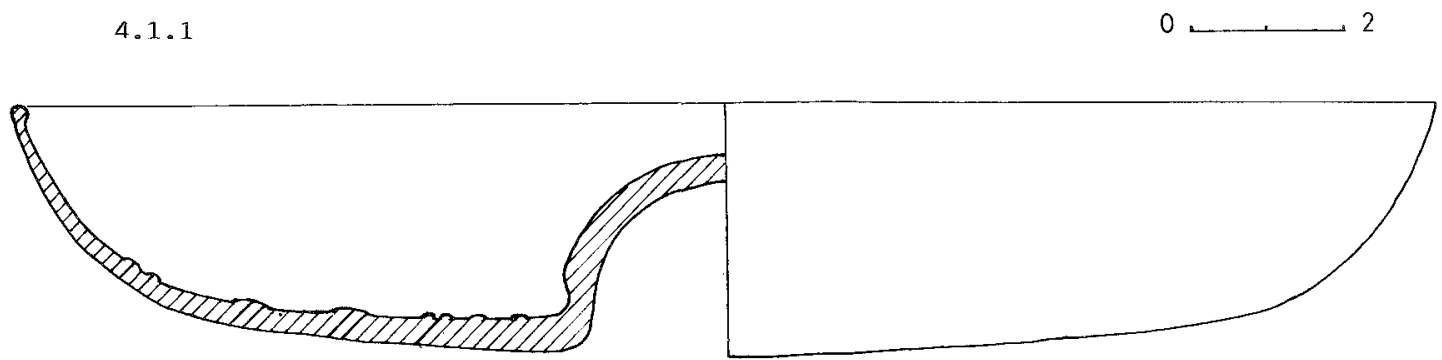

Fig. 2. Patera umbilicata o phiale mesomphala de Cales.

vuelto al exterior, de labio plano. Pasta de color ocre, ligeramente granulosa y con vacuolas. El color de la superficie es asimismo ocre, y está profusamente decorado con motivos geométricos. La decoración se articula en campos horizontales (de los que sólo se conserva el superior) delimitados por grupos de una banda central y un trazo paralelo a cada lado, y divididos verticalmente por líneas onduladas paralelas de las que se conocen con el nombre de «cabelleras». Los espacios así delimitados se decoran en su parte superior por medio de una serie de trazos semicirculares concéntricos y, en la inferior, por dos grupos de círculos concéntricos más pequeños, todo ello de color castaño oscuro. La parte superior del borde está decorada asimismo con una serie de ondas del mismo color. En la superficie del vaso se aprecian varios agujeros de lañado de aproximadamente 4,5 milímetros de diámetro.

4.2.3. ( $\mathrm{N}^{\circ}{ }^{\circ}$ de orden $5 ; n .^{\circ}$ de inventario 1.913 y 1919 ; figs. $3 \mathrm{e}$ y f). Dos fragmentos de recipientes bitroncocónicos, quizás botellas, de pasta de color castaño y rojizo respectivamente, con superficie alisada en ambos casos y restos de motivos decorativos de color castaño, muy perdidos. En la número 13 parecen corresponder a dos bandas 


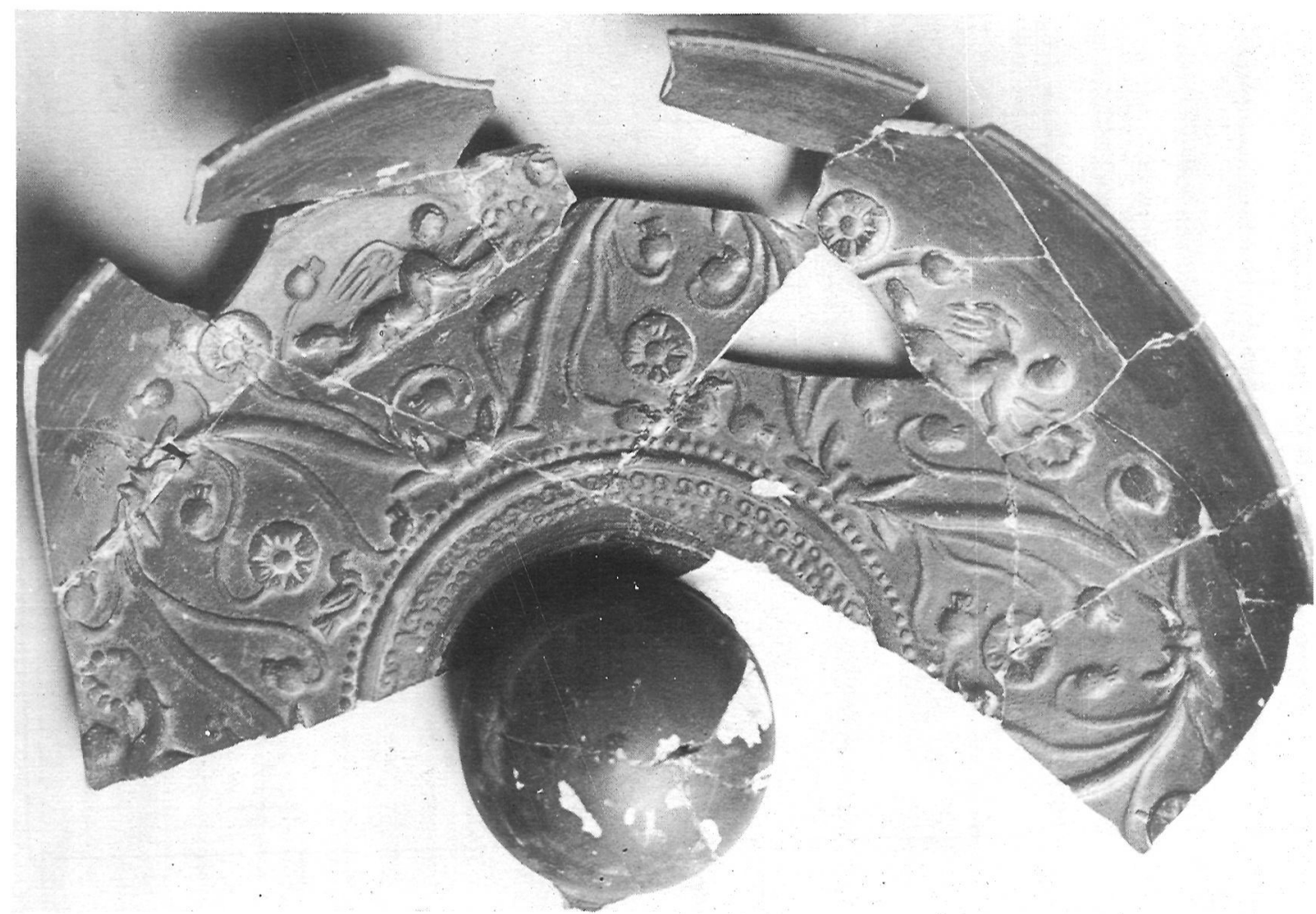

Patera umbilicata de Cales (la Serreta, Alcoy) (4.1.1)

paralelas en el tercio superior del vaso y a círculos concéntricos entre ellas, pero es difícil precisarlo. El pie es indicado en ambos casos, y el fondo cóncavo. El número 1.913 presenta el arranque del cuello, aunque la rotura impide precisar cómo se resolvía el borde; tal vez se tratara de un borde vuelto exterior, quizás en forma de cabeza de ánade.

4.2.4. (N. ${ }^{\circ}$ de orden $19 ; n .{ }^{\circ}$ de inventario 1.916; fig. $3 \mathrm{~g}$ ). Parecido a los anteriores es otro fragmento de cuerpo y boca de un recipiente de tendencia ovoide o esférica, cuello muy corto y borde vuelto exterior ligeramente engrosado. Pasta amarillenta con engobe blanquecino y decoración de color castaño oscuro. Lo conservado recuerda bastante a otro ejemplar de La Serreta de Alcoy, tanto por su forma como por su decoración (NORDSTRÖM, 1969, fig. 25, 8).

4.2.5. ( $\mathrm{N} .{ }^{\circ}$ de orden $5 ; \mathrm{n}^{\circ}{ }^{\circ}$ de inventario 1.911; fig. 4c). Vaso formado por un cuerpo elipsoide horizontal, pie de anillo, largo cuello troncocónico invertido y borde vuelto exterior. Pasta de color gris muy oscura, con desgrasantes calizos y vacuolas. Espatulado horizontal en la superficie, que adquiere un tono algo más claro que la pasta. Es uno de los típicos vasos caliciformes tan frecuentes en la cerámica ibérica levantina.

4.2.6. $\left(\mathrm{N} .{ }^{\circ}\right.$ de orden $26 ; \mathrm{n} .^{\circ}$ de inventario 1.921 ; fig. 4a). Plato ibérico de pared troncocónica invertida, con pie anular y borde recto ligeramente exvasado con engrosamiento en su parte superior. Pasta fina, con desgrasante de color negro y algunas vacuolas, de color rojizo en la parte central y castaño en los laterales. Superficie alisada, de color ocre en la parte inferior y amarillenta en la superior. Decoración interna y externa a base de grupos de filetes castaños de diferente grosor y densidad. 

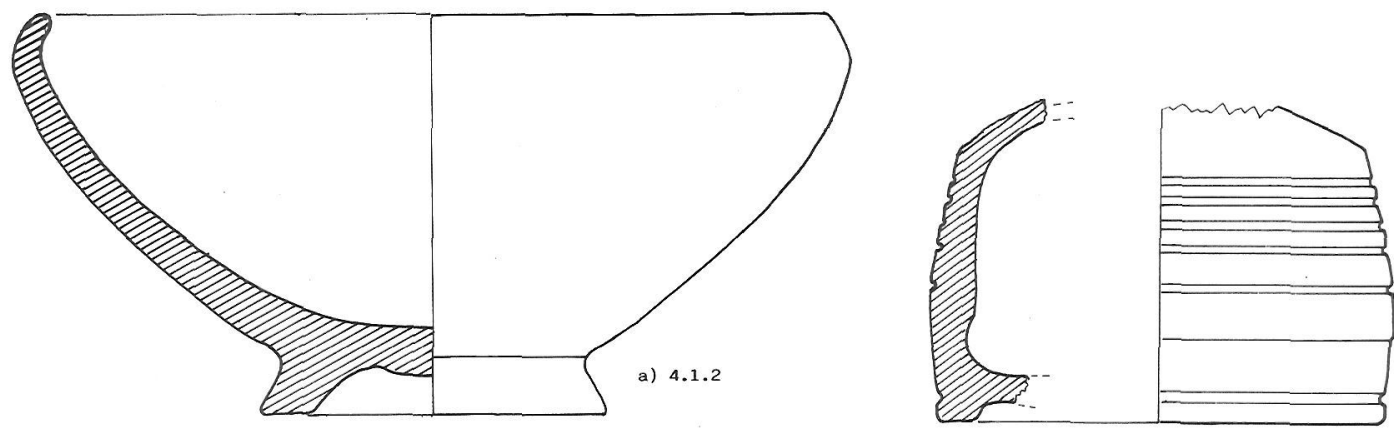

b) 4.1 .3
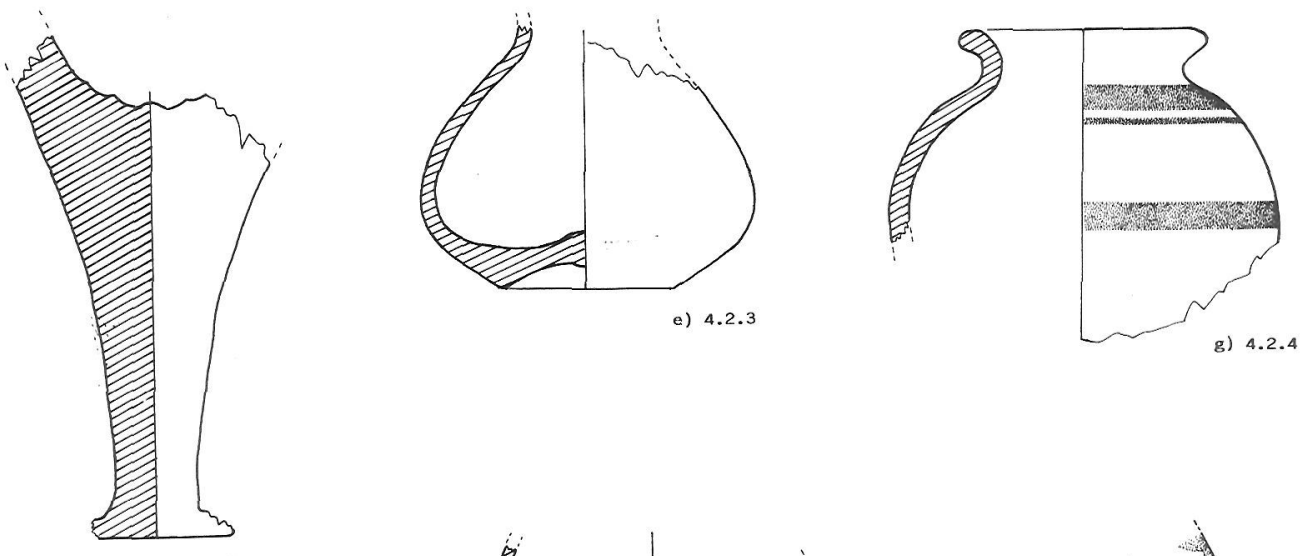

c) 4.2 .1
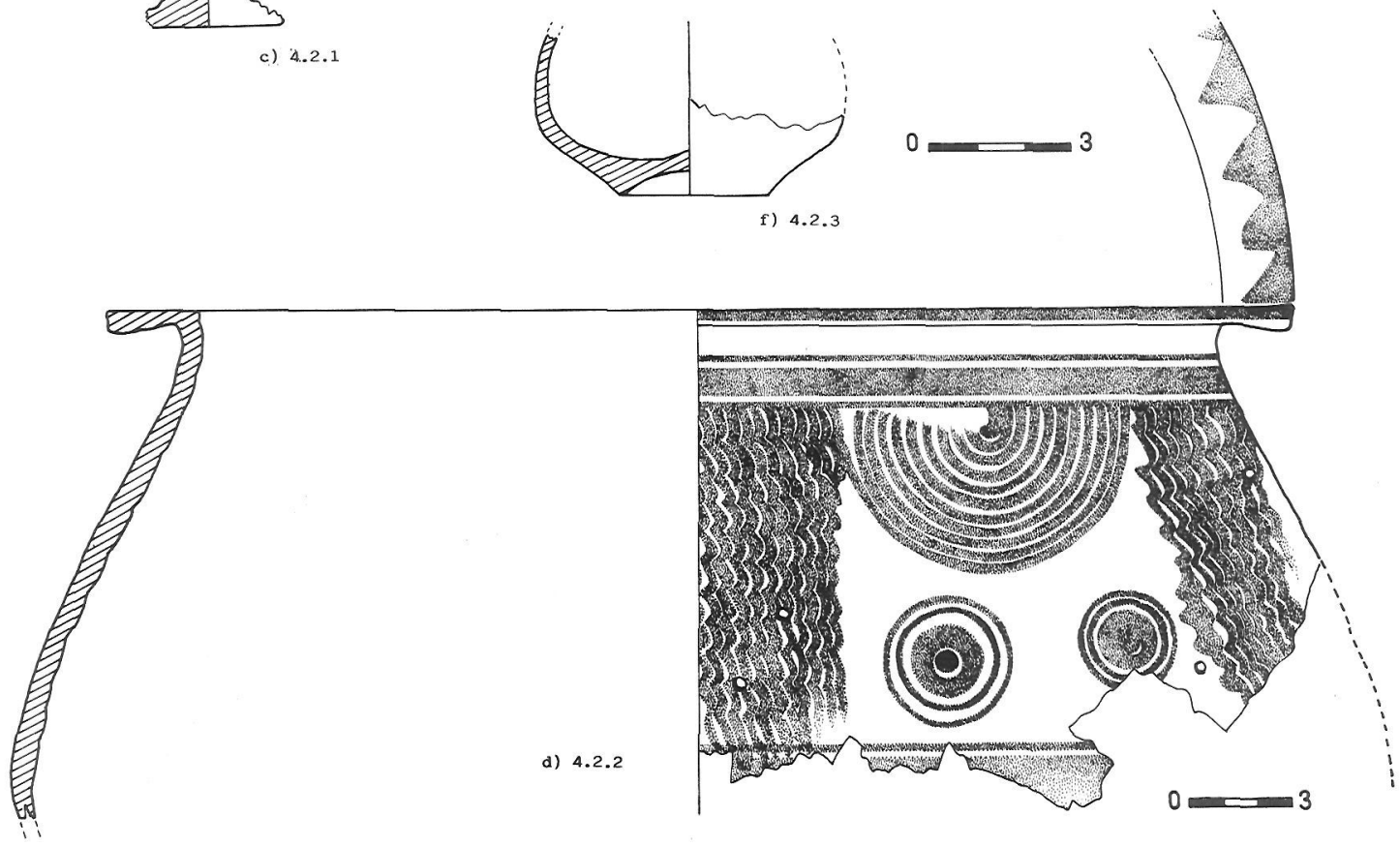

Fig. 3. Cerámica de barniz negro (a, b) e ibérica (c, d, e, f, g). 


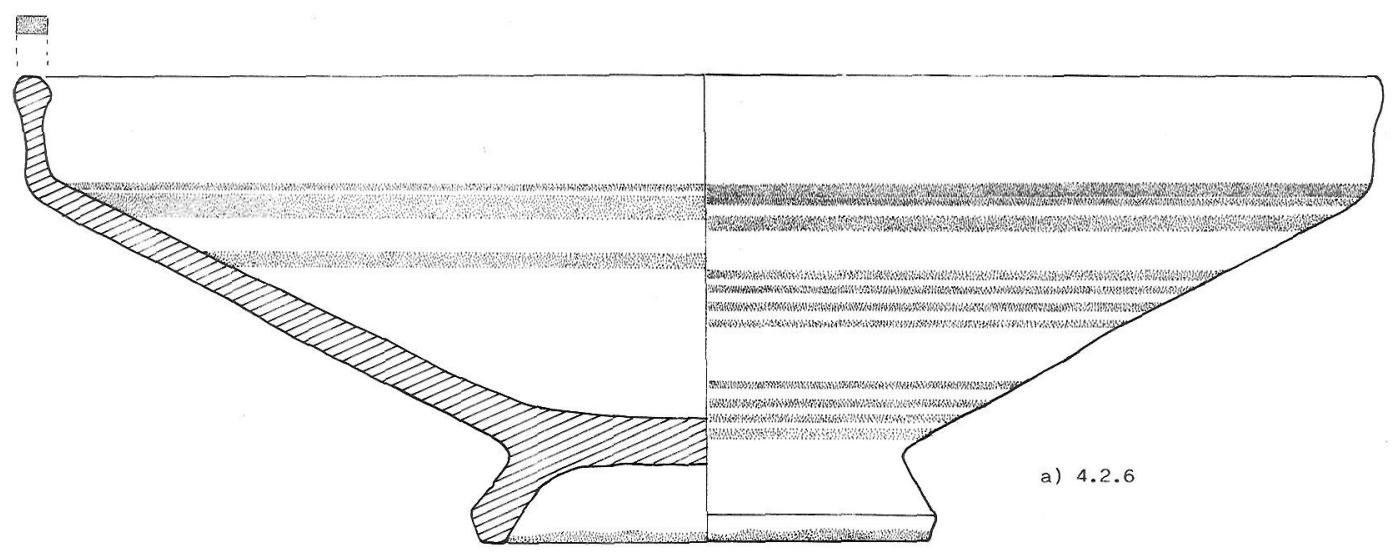

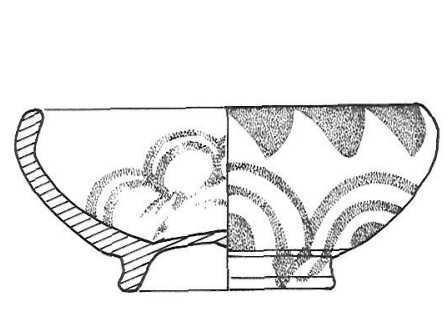

b) 4.2 .7

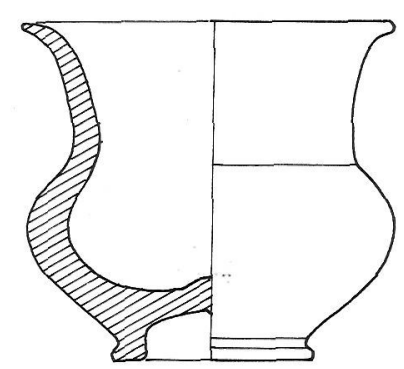

c) 4.2 .5

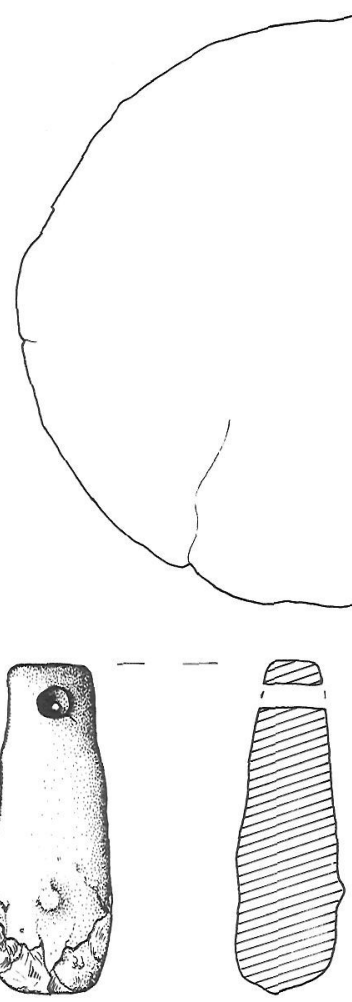

f) 4.3 .2

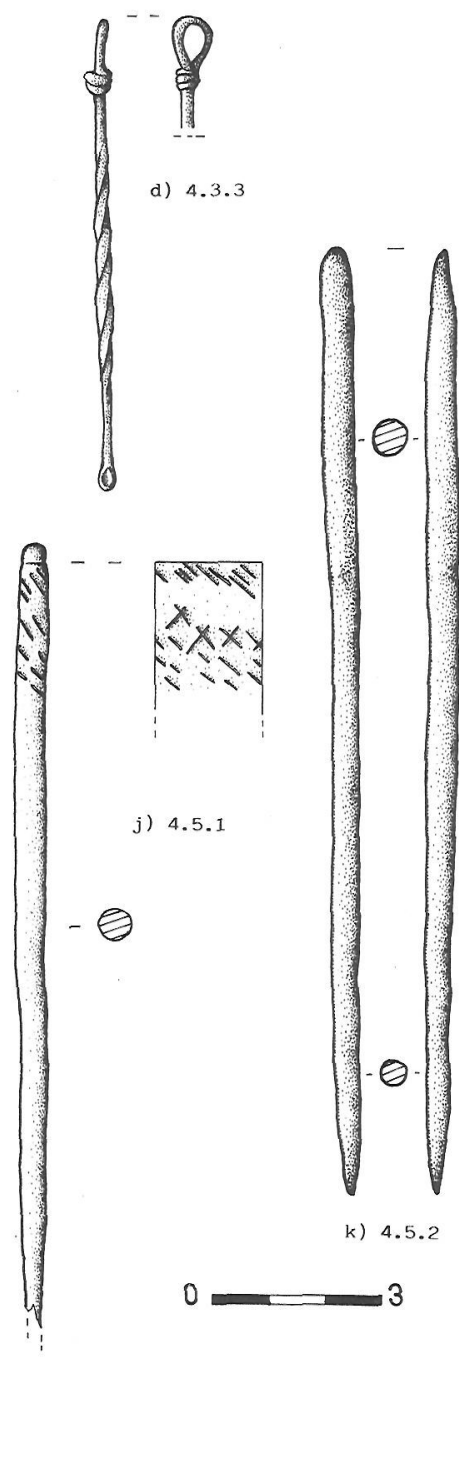

Fig. 4. Cerámica ibérica $(a, b, c)$, objetos metálicos (d, e, f), de terracota $(g, h, i)$ y de hueso $(j, k)$. 


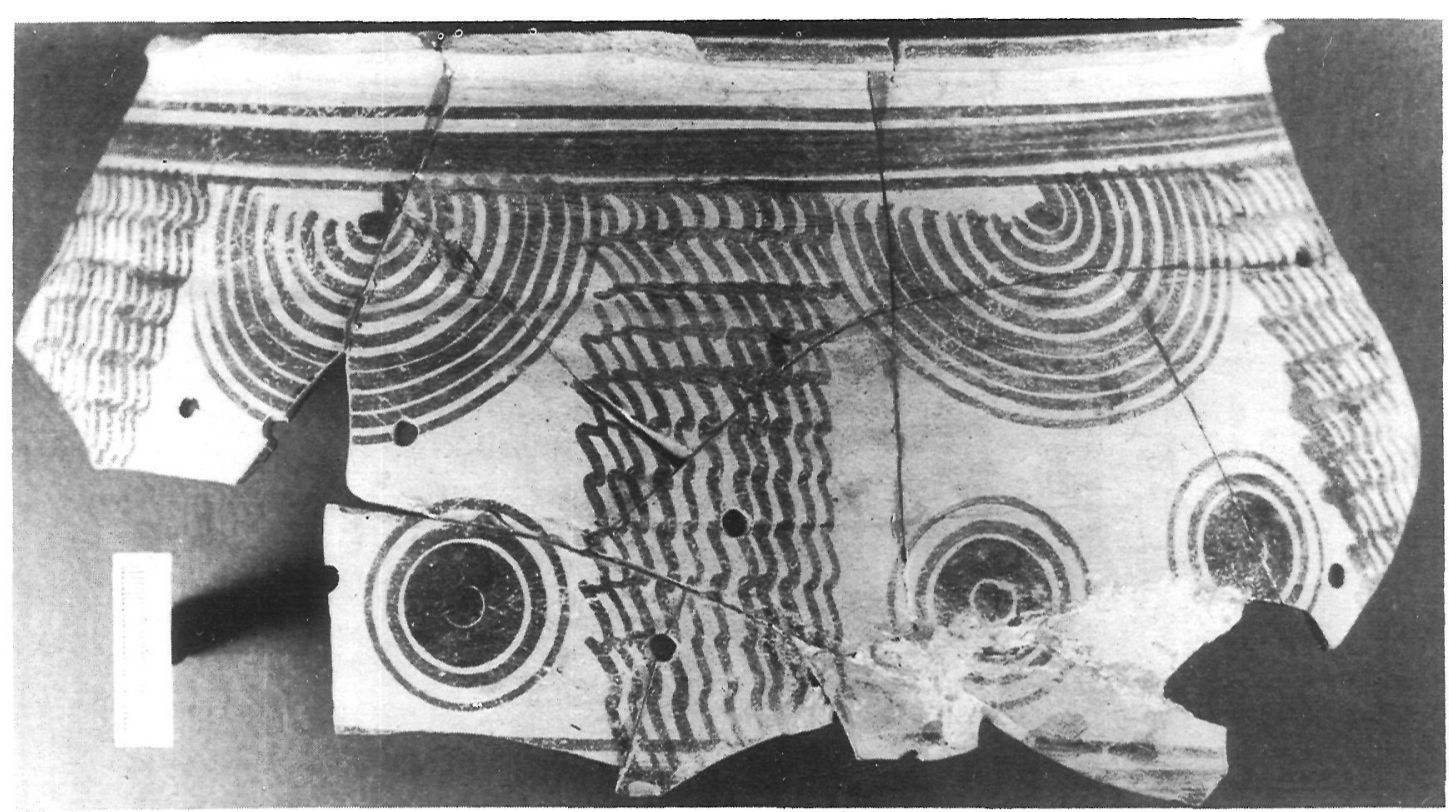

Vasija ibérica (4.2.2.) de la Serreta (Alcoy)

4.2.7. ( $\mathrm{N} .{ }^{\circ}$ de orden $24 ; n .{ }^{\circ}$ de inventario 1.918; fig. $4 \mathrm{~b}$ ). Cuenco de pasta fina de color ocre con engobe más claro y decoración geométrica pintada en tono castaño oscuro por el interior y el exterior; semicírculos concéntricos y triángulos colgantes en el exterior, e hileras de semicírculos concéntricos, formando arquillos, en el interior. Borde ligeramente reentrante.

\subsection{Objetos metálicos}

4.3.1. (N. ${ }^{\circ}$ de orden $4 ; n .^{\circ}$ de inventario 1.905 ; fig. 4e). Disco de plomo de sección cilíndrica, contorno bastante regular y 207,77 gramos de peso. Con el número 1.904 está registrado en el inventario moderno del Museo un «bronce en forma de tapadera circular», en tanto que en el antiguo este número designa una «pieza de cerámica indeterminada», por lo que no podemos saber si realmente se encontraron uno o dos de estos plomos. Tampoco hemos podido encontrar el ponderal de bronce $\left(n .^{\circ}\right.$ de orden 29$)$ a que se alude en el libro de registro.

4.3.2. ( N. $^{\circ}$ de orden $29 ; n .{ }^{\circ}$ de inventario 1.930 ; fig. 4f). Pesa de telar de plomo, de forma aproximadamente trapecial y muy estropeada en su parte inferior, que debió sustituir en el mundo ibérico a las grandes pesas de terracota. Peso 139,82 gramos. Debía de formar un conjunto con las fusaiolas de tierra cocida que se relacionan más abajo.

4.3.3. (N. ${ }^{\circ}$ de orden $12 ; n .{ }^{\circ}$ de inventario 1.903 ; fig. $4 \mathrm{~d}$ ). Cucharita de bronce formada por una varilla de metal con un extremo ligeramente engrosado en el que se abre una pequeña cazoleta, y otro vuelto sobre sí mismo y enrollado al vástago principal, formando una pequeña anilla. La varilla se ha hecho girar sobre sí misma, produciendo unas estrías torsas que constituyen su única decoración.

\subsection{Objetos de terracota}

4.4.1. (N. ${ }^{\circ}$ de orden $7 ; n .{ }^{\circ}$ de inventario $1.908 ;$ fig. $4 \mathrm{~g}$ ). Fusaiola de sección esférica, de color ocre claro con gruesos desgrasantes. 
4.4.2. (N. ${ }^{\circ}$ de orden $-; n .{ }^{\circ}$ de inventario 1.929; fig. 4h). Fusaiola de sección bitroncocónica, rota en su parte superior; pasta fina, con núcleo de color rojo intenso y laterales grises; superficie gris, al parecer bruñida, decorada con incisiones y puntos que conforman una serie de cuatro líneas horizontales paralelas y, entre las dos superiores, una hilera de triángulos dobles con puntos en su interior. Puntos también existentes entre las dos líneas inferiores.

4.4.3. (N. ${ }^{\circ}$ de orden $6 ; n .{ }^{\circ}$ de inventario 1.907 ; fig. 4i). Fusaiola de sección ovoide, con líneas incisas horizontales e incisiones verticales e inclinadas más marcadas. Pasta de color gris oscuro.

\subsection{Objetos de hueso}

4.5.1. ( $N .^{\circ}$ de orden $15 ; \mathrm{n} .{ }^{\circ}$ de inventario 1.914; fig. 4j). Punzón de sección cilíndrica, roto por la punta, con una decoración incisa en su parte superior en forma de pequeñas líneas inclinadas, algunas de ellas formando aspas.

4.5.2. (N. ${ }^{\circ}$ de orden $18 ; n .{ }^{\circ}$ de inventario 1.920 ; fig. $4 \mathrm{k}$ ). Punzón de sección cilíndrica.

\section{Estudio del material}

\subsection{Cerámica de barniz negro}

Las piezas descritas bajo los números 4.1.1., 4.1.2. y 4.1.3. son las más importantes de todo el conjunto, ya que permiten establecer una cronología aproximada para el departamento en que aparecieron.Si recogemos la observación de C. Visedo de que éste mostraba una potencia de 1,50 metros, y observamos que las entradas de los recipientes de barniz negro en el museo tuvieron lugar los días 19. 05, 29. 06 y 13. 07, habríamos de concluir que, si realmente existió la estratigrafía de que se habla, el fragmento 4.1.3. debió aparecer en un nivel más profundo que los anteriores, muy próximo al 4.1.2. y lejos del 4.1.1. que correspondería al nivel más superficial. La mayor parte de las cerámicas ibéricas procederían asimismo de estos niveles superiores, mientras que en los inferiores el material sería más escaso, predominantemente fusaiolas y plomos. Pero como ya se ha indicado, esto es imposible de precisar, pues no tenemos datos fidedignos de cómo se desarrolló la excavación; pudo suceder que no se profundizara al mismo tiempo en todo el departamento, por lo que materiales aparecidos en días muy alejados podrían corresponder sin embargo al mismo nivel.

Comenzando por los niveles supuestamente inferiores, nos encontramos en primer lugar con el recipiente 4.1.3. (fig. 3b), descrito en el registro del museo como «tipo botella», que, debido a su estado fragmentario, es difícil de identificar. Podría tratarse de un tipo de pyxis de tradición griega, en la línea de las especies 7.741, 7.742 y 7.744 de Morel, datables entre los siglos III y I AC. Pero creemos más probable que estemos ante un recipiente de perfumes, tipo lekythos, catalogable dentro de la especie $5.410 \mathrm{de}$ Morel, a caballo entre las series 5.414, a la que por sus proporciones debería corresponder, y 5.416, en la que su hombro encuentra el más entrecho paralelo (5.416f1); una y otra se datan en el siglo IV AC, y en ambas abundan los productos de fábricas locales y regionales, (MOREL, 1981, 361); a una de éstas debe corresponder, por sus características de pasta y barniz, nuestra pieza. Su rareza se hace aún mayor si consideramos el estriado horizontal de su panza, ya que la decoración normal en este tipo de vasos es el acostillado vertical.

Mucho más fácil es en apariencia el estudio de la pieza 4.1.2 (fig. 3a), que corresponde a una forma L25 y que hasta no hace mucho tiempo se habría clasificado sin du- 
da como campaniense A. No obstante, los avances realizados en los últimos años en el conocimiento de este tipo de cerámica permiten precisar bastante su origen y cronología. En la nueva tipología de Morel, este vaso se incluye en la serie 2.732 , lo que viene confirmado por la relación entre R1 y R2, y se encuentra a caballo entre los tipos $2.732 \mathrm{~b}$ y $2.732 \mathrm{c}$, procedentes de Kouass y Rímini, respectivamente, y datados en el siglo III $\mathrm{AC}$, preferentemente en su segunda mitad, que se catalogan dentro de la "producción local o regional» (MOREL, 1982, 212). Su borde escasamente reentrante lo acerca a los tipos característicos del área púnica, en tanto los correspondientes al área etrusca serían bastante más cerrados. Su forma, L25, puede incluirse casi con toda certeza entre las producciones locales del Nordeste de España y del Languedoc Occidental (MOREL, $1980,112)$, siguiendo la tradición del taller de las páteras de las tres palmetas radiales y de los otros con él relacionados (SANMARTI, 1978, 554 ss; SANMARTI, 1978b, 22, 28 ss), una vez diferenciados claramente por la investigación estos talleres de los que produjeron la verdadera campaniense A, en la zona de Ischia (Nápoles).

Por su parte, el pie de este recipiente puede incluirse en el género P 200, y más concretamente en la serie $21 \mathrm{~b}$, que corresponde a cerámicas de fines del siglo III y de todo el II AC, muy frecuentes en la costa levantina, como puede observarse en numerosos ejemplares de Ampurias (SANMARTI, 1978, n. ${ }^{\circ}$ 19, 99, 162, 1.401). Por todo ello, la fecha que parece convenir a nuestra pieza son los últimos años del siglo III AC.

De mayor interés es la pieza 4.1.1 (fig. 2), que tipológicamente corresponde a la serie 2.173 de Morel, aunque no coincide exactamente con ninguno de los tipos tomados como modelo; está más próxima a los $2.173 \mathrm{c}$ y d, aunque la forma del umbilicus recuerda más al 2.173b. En cualquier caso, corresponde a la cerámica denominada de Cales, datada en la segunda mitad del siglo III AC y más concretamente en su último tercio.

La cerámica de Cales se incluye entre las helenísticas de barniz negro de origen itálico, muy posiblemente etrusco (MOREL, 1980, 95), y fue la primera a la que se le dedicó un detallado estudio de conjunto (PAGENSTECHER, 1909). Sin embargo, mientras otras cerámicas de barniz negro han sido objeto en los últimos años de importantes trabajos (SPARKES \& TALCOTT, 1970, para las áticas; BALLAND, 1969 para las etruscas; MOREL, 1981 para las campanienses, etc.), los estudios sobre la cerámica calena se han limitado casi exclusivamente a consideraciones sobre la ya citada obra de Pagenstecher, a añadir los nuevos especímenes descubiertos y a plantearse la conveniencia o no de seguir utilizando el término «caleno». Este se acuñó en el siglo XIX, cuando apareció una gran cantidad de cerámica de este tipo en la zona de la antigua Cales (hoy Calvi Risota, en la provincia de Nápoles), ciudad a la que los textos clásicos (CATON, De agr., 135; VARRON, Apud Non., 545) adscribían una fuerte producción cerámica. Tradicionalmente se ha venido aceptando esta adscripción, tanto por la autoridad de las fuentes clásicas citadas como por el hecho de que no son pocas las piezas firmadas en las que junto al nombre del autor aparecen las palabras Calenos o Calebus, haciendo referencia

(1) PAGENSTECHER, 1909, 147 ss. Las cerámicas de barniz negro cuyo origen caleno está atestiguado por inscripciones son las siguientes: Páteras con medallón en altorrelieve: $\mathrm{n} .^{\circ} 101$, con busto de Sileno y leyenda $L . C A N O L E I V S L$. F. FECIT CALENVS. Páteras con ónfalos:.$^{\circ}{ }^{\circ} 114$, rapto de Proserpina; n. ${ }^{\circ} 115$, cuádriga de Helios; $\mathrm{n} .{ }^{\circ} 117$, cortejo báquico, todas ellas con la leyenda $L . C A N O L E I O S L . F . F E-$ CIT CALENOS; $\mathrm{n} .^{\circ} 121$, con erotes y la leyenda K. SERPONIOS CALIIB FIICII VEQO IISQILINO. C. $S$; $\mathrm{n}^{\circ}{ }^{123}$, erotes cazando, leyenda $L . C A N O L E I O S L . F . F E C I T C A L E N O S$; $\mathrm{n}{ }^{\circ} 133$, decoración vegetal, leyendas RETVS GABINIO C. S. CALEBVS FECIT E (tres ejemplares), C. GABINIO L. F. T. N. $C A L E N O$ (un ejemplar), L. CANOLEIOS L. F. FECIT CALENOS. Hay también inscripciones en páteras sin decoración en relieve: n. ${ }^{\circ} 142, L$. CANOLEIOS L. F. FECIT CALENOS; n. ${ }^{\circ} 143$, ANOLEI CIT CA$L E N V S$. Queda claramente establecido, por tanto, el origen caleno para las piezas firmadas por Canoleius, Serponius y Gabinius y para aquellas otras de las que pueda afirmarse sin posibilidad de error que salieron de sus talleres. 
al origen del ceramista la primera y al lugar de fabricación la segunda (1). Una de las piezas en que se basa esta afirmación es precisamente una patera umbilicata con decoración de erotes del Museo de Nápoles, muy semejante a la de Alcoy (4.1.1) aunque de bastante mejor calidad, y en la que la línea de postas que rodean el umbo ha sido sustituida por la leyenda $K$ (aeso) Serponio(s) Caleb(us) fece(t) veqo Esqelino (PAGENSTECHER, 1909, 80, 144 s, lám. 13). Con base en esta mención del Vicus Esquilinus, P. Mingazzini $(1958,226)$ ha postulado el origen romano de esta pieza, ya que dicho topónimo se encuentra atestiguado en Roma. Pero en otros trabajos posteriores se sigue defendiendo su origen caleno (SANESI, 1978, 75 ss), ya que por una parte Calebus parece un ablativo locativo y por otra una inscripción de la propia Cales menciona un $\mathrm{Vi}$ cus Palatius que muy bien pudiera corresponderse con un no atestiguado Vicus Esquilinus. A todo ello hay que añadir que recientes excavaciones en Cales han sacado a la luz una ciudad de intensa actividad constructora y algunos fragmentos de moldes de cerámica calena (JOHANNOWSKY, 1961, 267, fig. 19; SANESI, 1976, 192, fig. 1). No obstante, hoy en día se acepta la existencia de una multiplicidad de alfares que produjeron cerámica «calena»; así, por ejemplo, en Lucania (hay un molde en el Museo de Paestum), Apulia, Sicilia (JENTEL, 1968; MOREL, 1981, 144 s), y, sobre todo, Etruria. Tras los estudios de A. Balland sobre las cerámicas estruscas de barniz negro, ha quedado claro que páteras de este tipo se fabricaron en los talleres de Malacena, en Etruria, como demuestran sus característica técnicas y la típica decoración etrusca de estampillas en relieve con palmetas y flores de loto que rodean su umbo (BALLAND, 1969, 101 ss). La datación de estas cerámicas etruscas, a lo largo del siglo III y en los primeros años del II AC, encaja también con la de los ejemplares de este mismo tipo y parecida decoración encontrados en Volterra (MONTAGNA PASQUINUCCI, 1972, 284, $351 \mathrm{~s}$ ). Todo ello nos ilustra sobre la complejidad del estudio de la que se ha venido denominando cerámica calena, a lo que contribuye el que bajo esta denominación se incluyan también vasos que sólo tienen con la calena una lejana semejanza (MOREL, 1980, 95). El recipiente de Alcoy parece ser una obra auténticamente calena, según se desprende del cotejo de su decoración con el vaso del Museo de Nápoles más arriba estudiado.

La cerámica de Cales decorada con relieves en su interior se incluye en el grupo de las cerámicas helenísticas con decoración en relieve. G. Richter ha demostrado que al menos algunas de ellas derivan directamente de las páteras metálicas griegas de la época clásica, tanto que éstas sirvieron en ocasiones de positivo para la confección de moldes. Existen testimonios irrefutables de este proceso en las páteras más lujosas, decoradas con escenas de cuádrigas (RICHTER, 1941, 383 ss), pero también siguen modelos metálicos algunas otras más sencillas, como una con decoración de palmetas y flores de loto de Cales, prácticamente idéntica a una copa de plata de Itaca (SANESI, 1976, 193).

Las paterae umbilicatae, también llamadas phialai o páteras con ónfalos, constituyen, junto a las páteras con medallón central y los gutti, los tipos principales de la cerámica calena. Alrededor de su umbo central se desarrolla una temática decorativa con las aventuras de Ulises, cuádrigas, cortejos báquicos, erotes, adornos vegetales, etc. Las firmas que orlan el umbilicus, a las que ya nos hemos referido, son de los más antiguos monumentos de la epigragía latina (nominativo en -os, ablativo en -ebus) y han permitido la identificación de talleres, algunos de ellos familiares, como el de los Gabinii, que ocupan buena parte de los siglos III y II AC. Junto a éstos, otros nombres como $L$. Canoleius, $K$. Atilius, etc., llenan la época de esplendor de la cerámica calena, entre el 250 y el $180 \mathrm{AC}$. (ROCCO, 1959, $271 \mathrm{ss}$ ), aunque parece que su producción continuó aún durante cierto tiempo.

En la Península Ibérica, la cerámica calena no es especialmente abundante. La primera noticia que de ella se tuvo corresponde a un pequeño fragmento, tal vez del meda- 
llón de un guttus o de la banda decorada de una patera umbilicata, con parte de la figura de un caballo en relieve (GARCIA Y BELLIDO, 1952, 389). Posteriores estudios han ido ampliando el catálogo de esta cerámica, que pese a todo sigue siendo bastante exiguo; sólo se han contabilizado como tal, además del ya citado, varios fragmentos de Cartagena, encontrados en un contexto de los siglos III-II AC, y correspondientes a un fondo de pátera con medallón de Orfeo en relieve, una patera umbilicata con decoración vegetal y un cuenco cuyo fondo interno está ornado asimismo con relieves de tipo vegetal (DOMERGUE, 1969, 159 ss); y otro de la mina Diógenes de Ciudad Real (DOMERGUE, 1969, 159 ss; BELTRAN LLORIS, 1975, 59 ss). No todos ellos, sin embargo, parecen corresponder a cerámicas estrictamente calenas. A este sucinto inventario hay que añadir, además, un ejemplar recientemente aparecido en el Tossal de Manises de Alicante, correspondiente asimismo a una patera umbilicata con escenas de navegación, posiblemente los viajes de Ulises, cuyo conocimiento debemos a la amabilidad de nuestro colega $\mathrm{E}$. Llobregat. Con estos recipientes hay que poner en relación, al menos formalmente, una serie de páteras metálicas con umbo central y decoración repujada o incisa en su pared interior: las páteras de Perotitos (OLMOS, 1982) y de Tivissa (SERRA RAFOLS, 1941, 15 ss; 1964-65, 105 ss; RADDATZ, 1969, 251 ss; BLAZQUEZ, 1977, $221 \mathrm{ss}$ ), de cronología discutida, pero helenística en cualquier caso, que adornan su umbo central con una cabeza de felino.

Asimismo son relativamente numerosos otros vasos, por regla general cuencos o páteras, decorados en su fondo interno con un medallón en relieve en forma de cabeza o de busto humano. En este grupo se incluyen el fragmento de Cartagena antes mencionado, otro de Sagunto (ARANEGUI Y GIL MASCARELL, 1978, 13 ss), y un vaso casi completo de Calviá (Mallorca) en cuyo medallón se representan los bustos de Isis y Serapis. A diferencia de los demás, éste es de barniz rojo y se ha propuesto para él un origen siciliano (BLECH, CAMPS Y VALLESPIR, 1978, 231 ss). De barniz negro son, en cambio, dos fragmentos de Villafranca del Penedés (Barcelona), en cuyo medallón central se representan respectivamente un busto y una cabeza femenina (RIPOLL Y BARBERA, 1968, 305 ss), y uno del Castell de Almenara (Castellón), con medallón en forma de cabeza femenina, tal vez, como indica su editor, de gorgona (GUSI, 1974, $119 \mathrm{ss}$ ). Muy interesante es el hecho de que estas tres últimas piezas compaginen la decoración en relieve con otra pintada con motivos geométricos o vegetales por el interior $y$, en menor medida, también por el exterior. De este modo se han de incluir necesariamente en el amplio conjunto de cerámicas pintadas helenísticas conocidas genéricamente como «de Gnathia», pero que en realidad corresponden a una serie de grupos cuya ordenación y clasificación dista mucho de estar ultimada (cerámicas de las Pendientes Occidentales, de los medallones en relieve, de Gnathia propiamente dicha, de Hadra, de Teano, vasos de Pocolom y, en último término, incluso la campaniense $\mathrm{A}$, por citar sólo aquellos cuya decoración pintada se aplica sobre un fondo de barniz negro), pero cuya cronología puede fijarse, grosso modo, entre las últimas décadas del siglo IV y las centrales del siglo II AC. (MOREL, 1980, 89 ss).

A este mismo tipo cerámico pertenece una pátera de la necrópolis de La Albufera de Alicante (NORDSTROM, 1961, 54; fig. 5a), que ha perdido casi todo el barniz negro que la recubrió en su día. En el centro de su fondo interno tiene un medallón en relieve con una cabeza que parece corresponder a una gorgona; a su alrededor, un friso de trazos ondulados en forma de eses muy estilizadas que hoy aparecen como incisas en la superficie, pero que en su día pudieron estar recubiertos de pintura blanca. Su pie anular, alto y recto, le asigna una cronología bastante antigua.

El motivo de la gorgona se encuentra también en lo que parece el umbo de una pátera metálica procedente de Mogón (Villacarrillo, Jaén), que sería el equivalente en plata de estas piezas cerámicas. 
$\mathrm{Al}$ contrario de lo que se ha venido indicando con cierta frecuencia, este tipo de cerámicas con medallón central no es corriente entre los productos de Cales. En el repertorio de Pagenstecher, sólo una pátera con medallón, perteneciente al taller de L. Canoleius, lleva la indicación Calenus; otras aparecen firmadas por Gabinius, que en algunas paterae umbilicatae hace mención también de su origen caleno (PAGENSTECHER, 1909, 68). En fechas recientes se las ha venido identificando como cerámicas de Teano (MOREL, 1965, 57) o de procedencia muy variada; Gnathia, Tarento, Canosa, Campania, etc. (ARIAS, 1963, 475 ss; JENTEL, 1968, 21). El reciente estudio de Jentel sobre los gutti y askoi etruscos y apulios ha demostrado que en ellos son bastante frecuentes los medallones con cabezas humanas cubiertas con piel de león y también con cabezas de gorgonas, semejantes a las que encontramos en páteras cerámicas y metálicas en la Península Ibérica (JENTEL, 1978, passim; especialmente, 141 ss). Es de suponer que otro tanto ocurra en páteras y cuencos de la misma procedencia.

Dentro de estas cerámicas de medallones en relieve del Mediterráneo Occidental merecen mención especial las llamadas Arethusaschalen y Heraklesschalen. Las primeras son copas cuyo medallón está formado por el aplique de un molde obtenido de una decadracma de Siracusa de finales del siglo V AC, en muchos casos con la leyenda intencionadamente borrada. Hoy en día ya no se incluyen entre las cerámicas de Cales, como en su día hizo Pagenstecher, sino entre las de Teano (MOREL, 1980, 91) u otros centros de producción itálicos (RIZZO, 1946, 246 ss). Las segundas son páteras de la forma 1.534 de Morel, cuyo medallón lo ocupa una figura de Hércules de pie, fabricadas en los alrededores de Roma en la segunda mitad del siglo III AC. (MOREL, 1980, 93); uno de los escasos ejemplares conocidos procede del Tossal de Manises de Alicante, aunque hoy, desgraciadamente, se ignora su paradero (LAFUENTE, 1959, 26, lám. VII).

Frente a la moda imperante años atrás, que quería ver en todos estos objetos directas importaciones áticas o suritálicas, hoy adquiere cada vez mayor validez la idea de que un gran número de ellos corresponden a producciones regionales o locales, que tienen en común con sus modelos una semejanza de forma y tipos, pero de los que se diferencian en muchos aspectos: composición de la pasta y calidad del barniz, entre otros (MOREL, 1978, 153). Junto a los ejemplos ya citados, podemos traer a colación el caso de los cuencos con prótomos en relieve en el centro de su fondo interior, identificados en Volterra como producción muy probablemente local (MONTAGNA, 1972, 284, $385 \mathrm{ss})$.

Hay que destacar el hecho de que la mayor parte de las cerámicas de barniz negro con decoración en relieve que conocemos en la Península Ibérica procede de yacimientos de la costa mediterránea o, en todo caso, de otros con ella relacionados y de importancia estratégica o comercial destacada. Ello no es de extrañar si tenemos en cuenta que se trata de las áreas más abiertas a las influencias griegas (en el sentido más amplio del término) y púnicas, culturas que eran las principales productoras y usuarias de este tipo de cerámica. Posteriormente, las cerámicas que acompañan a los ejércitos romanos en su marcha por la Península durante la segunda guerra púnica no encontrarán ningún obstáculo para su arraigo en esta misma zona.

La patera umbilicata de Alcoy, que está en el origen de esta digresión, es una de las pocas piezas conocidas en la Península cuyo origen caleno está fuera de duda. El hecho de que la calidad de su dibujo sea sólo mediana y de que carezca de inscripción, no disminuye su importancia, sobre todo si tenemos en cuenta que puede contribuir a ilustrarnos sobre los modelos tipológicos e iconográficos de algunos productos ibéricos. En ella encontramos ya al Eros-niño típicamente helenístico, que se imitará en páteras de plata ibéricas, como la de Perotitos. En la phiale de Alcoy aparecen entre plantas, posiblemente adormideras, con lo que podrían incluirse en el mismo ámbito dionisíaco en que se moverán los erotes ibéricos, que pronto pasan a tener un acentuado sentido funerario 

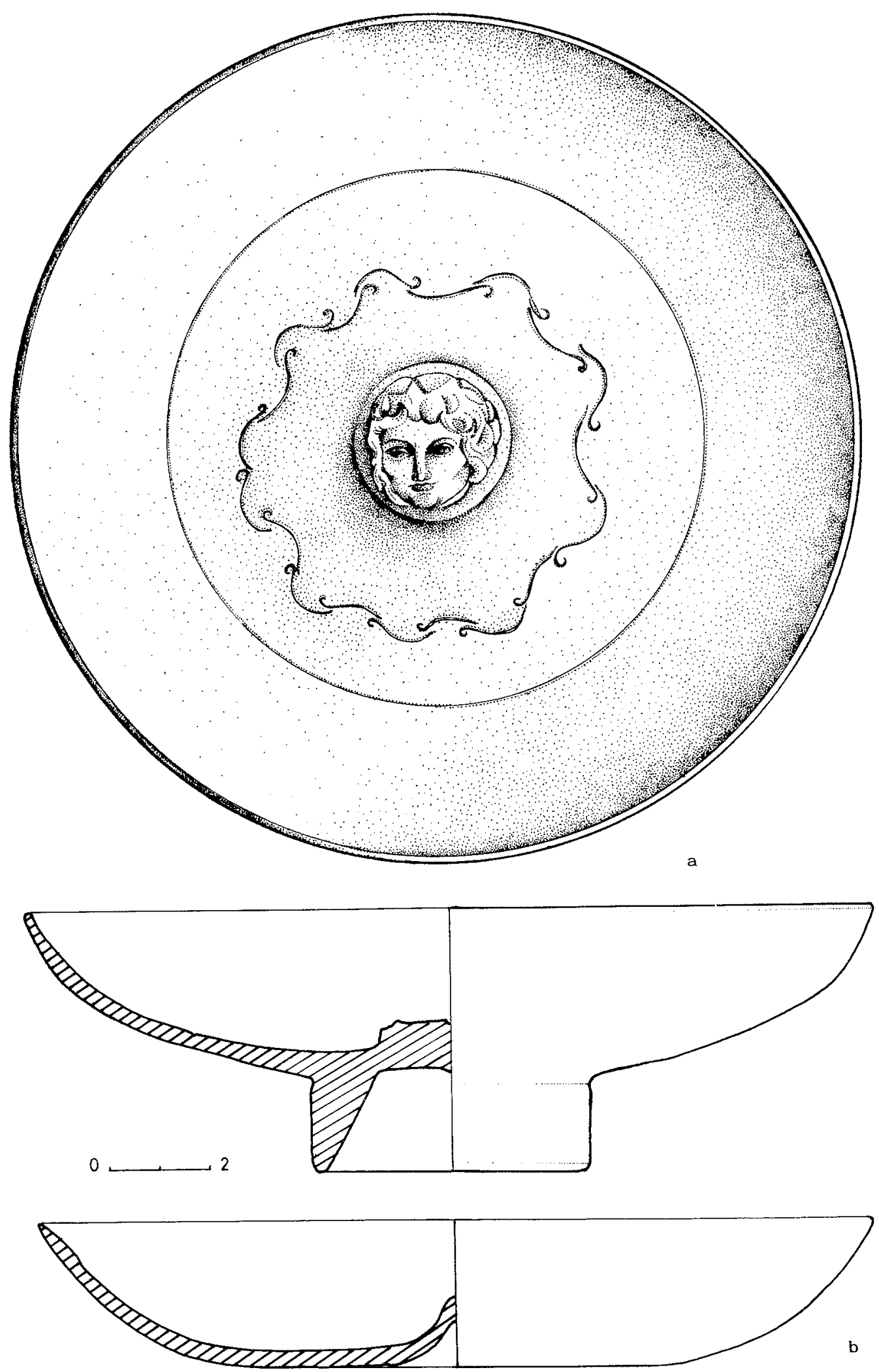

Fig. 5. Cerámicas de barniz negro (a) y gris (b) de La Albufereta de Alicante. 


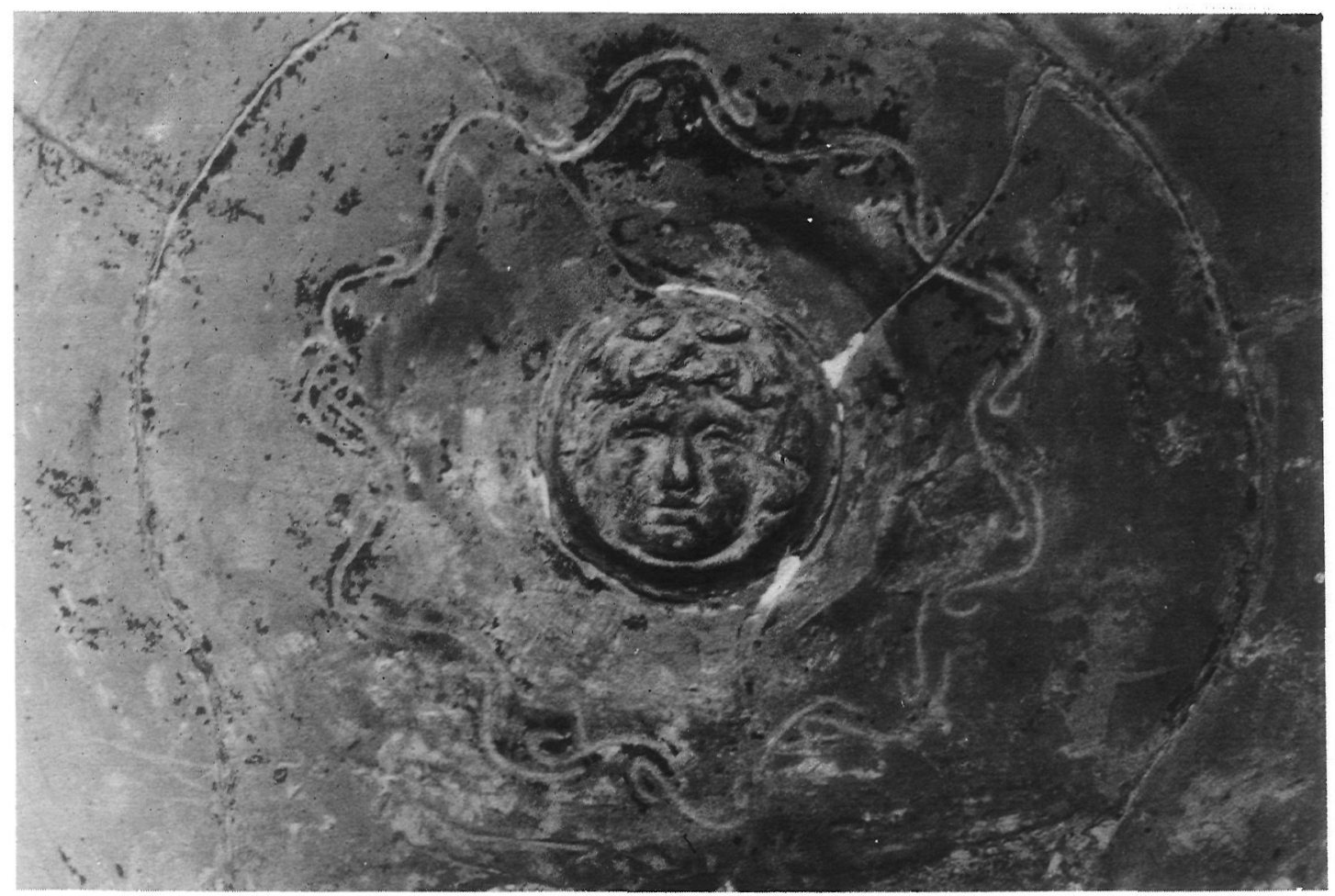

Cabeza de Gorgona de la figura anterior (5a)

(OLMOS, 1982, 21 ss). Los indigenas imitarán también la forma de la patera umbilicata, como demuestra la pequeña pátera de cerámica gris procedente de la necrópolis de la Albufereta de Alicante (NA-6.021) que reproducimos en nuestra figura 5b; el ónfalos se ha reducido a la mínima expresión, pero aún conserva el espacio suficiente para albergar al dedo que sostenía el recipiente en las ceremonias de libación.

No menos interesantes son los medallones de cabezas femeninas que ornan el fondo de páteras y copas del tipo que reproducimos en la figura 5a, procedentes asimismo de la necrópolis de la Albufereta (A-1.540). Su contemplación ha de traernos por fuerza a la memoria las caras femeninas de la Alcudia de Elche, características del período ibérico que comienza precisamente por estas fechas (RAMOS, 1982, $121 \mathrm{ss).} \mathrm{Aunque} \mathrm{la} \mathrm{re-}$ lación formal entre las cabezas femeninas de las cerámicas de barniz negro y las de la cerámica ibérica requiere aún un detenido estudio, parece que nos encontramos sin lugar a dudas ante una nueva manifestación del espíritu ibérico que hace suyos temas y motivos griegos, en muchos casos ya helenísticos, y, tras su reelaboración, los inserta en contextos muy alejados de aquel al que originalmente pertenecieron.

\subsection{Cerámica ibérica}

En su estudio renunciamos de antemano a la búsqueda exhaustiva de paralelos, ya que solamente nos interesa establecer, cuando sea posible, la cronología aproximada de cada pieza. Para ello recurriremos a las tipologías existentes, que son por desgracia muy pocas, y que en la mayoría de los casos tienen una finalidad más de ordenación formal que de fijación cronológica de los diferentes tipos cerámicos. Nos interesa asimismo, rastrear el origen y la evolución de algunas de las formas más interesantes, que pueden ser el equivalente indígena de piezas extendidas por el Mediterráneo Occidental. 
El ungüentario 4.2.1 (fig. 3c), del que sólo se conserva el pie, parece corresponder al tipo B de Cuadrado, y más concretamente a uno de los subgrupos B2, B3 o B4, con una cronología que grosso modo abarca entre el año 300 y el $75 \mathrm{AC}$, pero que puede centrarse en los últimos años del siglo III y durante todo el siglo II AC. (CUADRADO, $1977-78,389 \mathrm{ss})$. Se trata de un tipo de ungüentario de origen griego, como han puesto de relieve numerosos estudios, desde los primeros de Thomson (THOMSON, 1934, 472 ss) hasta los más recientes de L. Forti (FORTI, 1962, 143 ss) y E. Fabricotti (FABRICOTTI, 1980, 397 ss). La primera autora establece siete tipos, que van desde comienzos del siglo V hasta los últimos años del siglo II AC. Nuestro ungüentario se incluiría en el tipo V, datado en los siglos III-II AC y muy relacionado con el tipo IV, lógicamente algo más antiguo.

El recipiente 4.2.2 (fig. 3d), típicamente ibérico, se incluye, tanto por su forma como por su decoración, en un amplio grupo de vasijas con paralelos en numerosos yacimientos peninsulares. Parece claro que debe corresponder a una forma globular o, más exactamente bitroncocónica, con lo que se incluiría en el grupo 2 de las formas geométricas de S. Nordström, que la autora denomina «jarra pithoide». La rotura del vaso, del que sólo se conserva la parte superior, no permite conocer si los dos troncos de cono tenían la misma altura o si, por el contrario, la superior era más alta. Ello tiene cierto interés cronológico, ya que en el primer caso se incluiría en el tipo $2 \mathrm{~A}$, de cronología antigua (El Molar, La Solivella) y en el segundo, en cambio, en el 2B, algo más moderno (Albufereta, Puntal de Salinas, La Serreta, etc.) (NORDSTRÖM, 1969, 106, 172 ss). El hecho de que el borde del vaso sea vuelto al exterior y recto, propio de ejemplares de cronología avanzada, parece avalar la segunda hipótesis (NORDSTRÖM, 1969, 110). Hay que tener en cuenta, sin embargo, que el tipo de borde que presenta este recipiente es más propio de los llamados kalathoi, tanto de los que tienen el cuerpo recto como de los que lo tienen estrangulado, y que sólo raramente se encuentra en recipientes del tipo del 4.2.2, como remate de un cuello apenas indicado. El hecho de que sus paralelos más exactos dentro de la provincia de Alicante se encuentren en el mismo yacimiento de La Serreta, parece indicar que puede tratarse de un tipo local.

La decoración de este recipiente se incluye en el grupo B de la composición zonal de Nordström $(1969,119)$, aunque la rotura impide conocer si abarcaba toda la superficie del vaso o si, como parece más probable, se limitaba sólo al tronco de cono superior. Queda claro, de todas formas, que un grupo de banda central y filetes laterales recorría la línea de máxima anchura del vaso, y que su esquema decorativo está muy próximo a los típicos de la FG 2A y 2B de Nordström, con los motivos habituales en este tipo de cerámica (semicírculos concéntricos suspendidos, separados por grupos de líneas onduladas verticales y círculos concéntricos de relleno en la parte libre) (NORDSTRÖM, 1969, 130). Todos estos datos parecen convenir a una datación en la segunda mitad del siglo III AC, aunque siempre dentro de la imprecisión cronológica que caracteriza a este tipo de cerámica.

Los recipientes descritos en el número 4.2 .3 (fig. 3e y f) corresponden al tipo $2 \mathrm{~B}$ de Nordström; su forma de jarra pithoide y su pie cóncavo anguloso le otorgan, según esta investigadora, una fecha entre los siglos IV y II AC (NORDSTRÖM, 1969, 106, 114). Corresponden asimismo a la forma 21 de Cuadrado, aunque la tipología de este autor carece de valor cronológico (CUADRADO, 1972, 132 ss). El número 4.2.4 (fig. 3g), por el contrario, está más próximo a la forma 20 de Cuadrado y, según Nordström, es corriente a partir de los últimos años del siglo III AC. Lo conservado recuerda bastante a otro ejemplar del mismo yacimiento de La Serreta (NORDSTRÖM, 1969, fig. 25, 8), aunque es una forma muy extendida, incluso por Andalucía (LUZON, 1973, 43).

De mayor interés es el vaso caliciforme descrito en el apartado 4.2 .5 (fig. 4c). Corresponde al tipo FG6 de Nordström $(1969,107)$, característico de los siglos V-III AC. 
Se trata de una forma ampliamente difundida por toda la costa levantina, tal y como ha estudiado C. Aranegui $(1975,366 \mathrm{ss})$, que los interpreta como una derivación de los recipientes bitroncocónicos del momento de transición (siglos IV-III AC) entre las cerámicas grises más antiguas y los recipientes de pequeño tamaño más tardíos, cuyo representante más conspicuo será, desde finales del siglo III, la típica jarrita ampuritana. El hecho de que en el ejemplar que estudiamos el diámetro máximo no sea superior a la altu$\mathrm{ra}$, le confiere una relativa modernidad dentro de este proceso evolutivo.

Especial interés tiene el hecho de que estos vasitos sean muy frecuentes entre los materiales de numerosas cuevas ibéricas del País Valenciano, que acertadamente han sido calificadas como «cuevas-santuario» (GIL MASCARELL, 1975, 303 ss; 320 ss). Esta misma autora se hace eco de la tesis de Shefton $(1971,109)$ de que se trata de un tipo de vaso de origen aqueménida que se imita en cerámica ática de barniz negro y se difunde por todo el Mediterráneo. Los vasos caliciformes característicos de esta cerámica carecen por regla general de pie, tienen cuerpo gallonado o acostillado y suelen mostrar en el centro de su fondo interno un umbo con una cabeza en relieve. En cambio, los típicos del Mediterráneo Occidental se caracterizan por el añadido de asas y pie, convirtiéndose en verdaderas cráteras (formas L40D y E, Morel 3.521, frente a L41, Morel 7.411); tanto unos como otros son de cronología relativamente antigua (ss. IV-III AC). Los vasos caliciformes ibéricos parecen una simplificación de estos tipos: el cuerpo se ha alisado, han desaparecido las asas y el pie ha quedado reducido a la mínima expresión.

Las formas acostilladas y el umbo central de algunas de estas cerámicas de barniz negro, que las pone en relación con algunos de los tipos estudiados más arriba, parecen derivar directamente de modelos metálicos de plata, de los que hay numerosos ejemplos (STRONG, 1966, 99 ss; RADDATZ, 1969, 84; SPARKES \& TALCOTT, 1970, 122) y cuya cronología, a juzgar por los resultados de las excavaciones en el ágora de Atenas, se remonta a los años centrales del siglo IV AC.

En la Península Ibérica, vasos de plata de este tipo los encontramos en varios tesoros correspondientes a los siglos II-I AC (RADDATZ, 1969, 79 ss). Entre ellos destaca uno de los de Tivissa, con diez ejemplares que aparecieron asociados a cuatro paterae umbilicatae, también de plata, decoradas con cuádrigas repujadas una, con motivos vegetales y peces otra, y con una sucesión de figuras humanas reales y fantásticas, y de animales, grabados a buril y dorados a fuego, la tercera; ésta y la cuarta muestran asimismo en su umbo una cabeza de lobo. El estudio de este tesoro, como el de tantos otros, ha sido llevado a cabo por Raddatz $(1969,258$ ss; passim), que lo data en conjunto en torno al $170 \mathrm{AC}$. No obstante, los tesoros de Tivissa presentan numerosos puntos oscuros y han sido objeto de largas discursiones. Parecen existir tres tesoros: Tivissa I, descubierto en 1912 y compuesto por brazaletes, anillos, pendientes y 29 monedas; Tivissa II, encontrado en 1927 y compuesto exclusivamente por objetos de plata, vasos caliciformes, copas, páteras, collar y espiral. No se encontraron monedas en este tesoro, pero sí en otro aparecido en 1925 (Tivissa III) y compuesto por varios objetos de bronce, un denario romano, una moneda de imitación ampuritana y un as ibérico de Iltirda, que ha sido considerado como intrusivo. El tesoro número II, que es el que aquí nos interesa directamente, no cuenta con monedas que permitan fijar su cronología, pero el hecho de que el poblado al que debieron corresponder todos estos tesoros haya sido destruido violentamente, hace suponer a algunos investigadores que las ocultaciones debieron ser simultáneas y estar en relación con la Segunda Guerra Púnica o con las revueltas antirromanas inmediatamente anteriores. Raddatz (1969, passim) la establece en torno al año 170, pero Serra Ráfols $(1964-65,113,116)$ la coloca a finales del siglo III, más concretamente en el año $218 \mathrm{AC}$. Ambas fechas son meramente indicativas, ya que las excavaciones realizadas en el lugar de los hallazgos no proporcionaron materiales signi- 
ficativos, o éstos no fueron nunca publicados (SERRA RAFOLS, 1941, 20). Modernas investigaciones numismáticas, sin embargo, indican que la ocultación del tesoro número I tuvo lugar en la última década del siglo III AC, dato que creemos básico para determinar la fecha de destrucción del poblado (RIPOLLES, 1982, 107, 621). Aunque el tesoro número II carezca de monedas, parece lógico extrapolar esta fecha a los demás tesoros conocidos, ya que de las excavaciones de Serra Ráfols se deduce que tras su destrucción, el poblado no volvió a habitarse hasta la Edad Media.

Este mismo tipo de vasos caliciformes se encuentra también en representaciones escultóricas ibéricas, en manos de figuras femeninas como las damas oferentes del Cerro de los Santos y alguna de Osuna (GARCIA Y BELLIDO, 1980, figs. 35-37, 40, 42, 51, 66; OLMOS, 1982, $68 \mathrm{ss}$ ). La escultura ibérica presenta, como es sabido, numerosos problemas en cuanto a su cronología, y no es éste el momento de tratarlos en profundidad. Tradicionalmente se vienen datando las primeras en el siglo IV y las segundas en una fecha más avanzada, ya en época romana (GARCIA Y BELLIDO, 1980, 42 ss; $58 \mathrm{ss}$ ), pero estudios recientes han precisado algo más estạs fechas. En las damas del Cerro de los Santos, Blanco Freijeiro cree ver determinados rasgos que permitirían datarlas entre los siglos III y II AC. (BLANCO, 1981, 53). Para los relieves de Osuna, las excavaciones en la muralla de esta ciudad (CORZO, 1975) han proporcionado algunos datos arqueológicos que avalan la considerable subida de fecha que, con base en criterios principalmente estilísticos, ha defendido recientemente M. P. León $(1979,188$ ss); las escenas procesionales, precisamente aquellas donde aparecen los vasitos caliciformes, se datarían a finales del siglo III y comienzos del II AC.

De todo ello puede deducirse que el mundo ibérico hizo un continuado uso de este tipo de vasos, tanto en plata como en cerámica, a lo largo de los siglos IV, III y II AC, y que con frecuencia aparecen asociados a páteras umbilicatas, posiblemente como objetos de uso ritual o cúltico. En este sentido, no carece de interés recordar que en el departamento que estamos estudiando aparecieron juntos -quizá por mera coincidenciauna patera umbilica calena y el vasito caliciforme que acabamos de considerar.

El plato 4.2.6. (fig. 4a) corresponde a la forma FG1 de Nordström $(1969,106)$, que puede datarse, según esta autora, entre los siglos IV y I AC. C. Aranegui ha dedicado un estudio a los platos ibéricos de la Serreta, llegando a la conclusión de que todas las formas existentes derivan de modelos importados áticos o itálicos y que la decoración, cuanto más antigua, es más simple (ARANEGUI, 1970, $107 \mathrm{ss}$ ). El plato 4.2.6.se incluye en su tipología entre los de paredes curvas reentrantes, caracterizados por una decoración geométrica simple de bandas o, en los casos más complejos, por una decoración también geométrica de tipo bícromo, todo lo cual apunta hacia una cierta antigüedad en el conjunto de los platos ibéricos (ARANEGÚI, 1970, 115, 119). La inexistencia de una tipología más detallada de platos ibéricos impide lograr conclusiones más precisas, pero parece claro que se trata de una forma de imitación griega, semejante a la L27c (Morel 2.825 ) y datable en la primera mitad del siglo II AC. Su pie, encuadrable en el tipo Morel 235, proporciona asimismo una fecha de los siglos III-II AC. Corresponde al tipo P3C1 de Cuadrado, aunque como se ha venido indicando, esta tipología carece de valor cronológico.

El último plato, 4.2.7. (fig. 4b), corresponde al tipo FG6 de Nordström (1969, 107), de amplia cronología, aunque datable con preferencia entre los siglos V y III AC. La decoración interior que presenta puede cosiderarse según C. Aranegui «anterior al momento barroco de las decoraciones ibéricas» (ARANEGUI, 1970, 109 ss, 118). Está próxima a los temas 12 y 13 de Nordström $(1969,140$ ss), datables entre los siglos III y I AC. El tipo de plato es también de inspiración griega, $y$ recuerda poderosamente las formas L24 y L25, dentro de la especie 2.780 de Morel y, más concretamente, de la serie 2.784, correspondiente al siglo III AC. 


\subsection{Objetos metálicos}

Los discos de plomo como el que recogemos bajo el número 4.3.1 (fig. 4e) tienen una función difícil de precisar, pero creemos que pueden tratarse de ponderales, pues discos semejantes encontrados en otros lugares del Mediterráneo, en ocasiones llevan grabado el valor correspondiente (ROBINSON, 1941, n ${ }^{\circ}$ 2.450-55, lám. CXLVIII). Esta sospecha se torna en certeza si cotejamos el peso de este disco (207,77 gramos) con el que corresponde a los valores más altos de las series de ponderales ibéricos estudiados recientemente por D. Fletcher y C. Mata, que oscila entre 206,5 y 210,5. Se trataría, pues, de un múltiplo de la unidad ponderal ibérica equivalente a 48 dracmas del patrón euboico-ático de 4,36 gramos (FLETCHER Y MATA, 1981, 165 ss). Hemos de lamentar la desaparición de la pieza inventariada con el número 1.904, ya que si realmente se trataba de otro disco de plomo, el cotejo entre los pesos de las dos piezas podría haber confirmado plenamente la hipótesis arriba expuesta.

La pieza número 4.3.2 (fig. 4f), por el contrario, parece una simple pesa de telar, aunque su peso $(139,82$ gramos) la aproximaría a un ponderal de 32 dracmas $(139,52$ gramos) que no se ha encontrado, sin embargo, en ningún yacimiento ibérico.

De gran interés es la cucharita de bronce 4.3.3 (fig. 4d), que parece una cucharilla de tocador, aunque los paralelos más próximos, que pertenecen ya al mundo romano, los hemos encontrado entre los instrumentos quirúrgicos que constituyen el ajuar funerario de algunos médicos. Se trata de una especie de ligula cuyo extremo no ensanchado forma una pequeña argolla y parece que servían principalmente como sondas de oídos para fines médicos y de limpieza (MOLINA, 1981, 258; GALLIAZO, 1979, 162). Su aspecto es indudablemente clásico y no sería extraño que el ejemplar de Alcoy se tratara de una importación de alguna fábrica helenística suritálica.

\section{4.y 5.5. Objetos de terracota y de hueso}

Las fusaiolas y los punzones descritos corresponden a tipos muy comunes dentro del mundo ibérico, y su misma abundancia nos exime de citar paralelos.

\section{Conclusiones y cronología}

El estudio de los diarios de excavación, de los registros del Museo de Alcoy y de una serie de piezas de este mismo museo, nos ha permitido la identificación de un conjunto de materiales procedentes de las primeras excavaciones del yacimiento ibérico de La Serreta. Se trata de un conjunto bastante homogéneo perteneciente a un solo departamento y compuesto por algunos de los materiales típicos de los yacimientos ibéricos levantinos, con algunos añadidos de gran interés. La ausencia de ánforas y de grandes recipientes (con la única excepción de 4.2.2.) nos indica que no se trata de un almacén, y la aparición de objetos valiosos, como las cerámicas de barniz negro, entre las que destaca especialmente la de Cales, los pequeños vasitos ibéricos, la cucharilla, el ponderal, etc., nos demuestra que, sin lugar a dudas, se trata de una estancia de habitación, tal vez en la línea de los «gineceos» estudiados en su día por Llobregat $(1972,36)$. Es de gran interés constatar la aparición conjunta de una patera umbilicata de Cales y de un vasito caliciforme, que constituyen un ejemplo más de una arraigada asociación que se remonta a los prototipos metálicos de ambos vasos. Pero sería excesivo intentar extraer de ello cualquier otro tipo de conclusiones.

De especial importancia es la aparición de la cerámica de Cales, porque constituye uno de los pocos ejemplares de este tipo de cerámica encontrados en la Península Ibérica y porque permite el establecimiento de un término post quem para la cronología del 
departamento a mediados del siglo III AC. Todos y cada uno de los objetos encontrados pueden datarse entre los siglos III y II AC, aunque el estudio tipológico y de paralelos, hasta donde es lícito llegar con este tipo de materiales, permite agruparlos en las últimas décadas del siglo III AC y, en todo caso, en las primeras del siguiente. Correspondería, pues, a un momento central en la vida del poblado, y es de lamentar que la falta de una descripción más minuciosa de los trabajos de campo nos impida la recomposición de su estratigrafía.

Interesante es asimismo el constatar que muchas de las piezas aparecidas tienen un origen mediterráneo - helénico en su mayor parte - más o menos inmediato. Piezas de este tipo han servido de modelo a los indígenas para la realización material de algunas de sus obras, y quizás hayan constituido asimismo vehículo de transmisión de ceremonias, ritos y modos de pensar que, por su mismo carácter, son muy difíciles de aprehender en un estudio arqueológico. Todo ello viene a ser una prueba más de la apertura de la costa levantina hacia el Mediterráneo en la etapa inmediatamente anterior a la conquista romana, tal y como en su día apuntó en un sugerente trabajo, nunca plasmado por escrito, J. M. Luzón.

\section{BIBLIOGRAFIA}

ARANEGUI, C. 1970: «Cerámica ibérica de La Serreta (Alcoy): los platos». Papeles del Laboratorio de Arqueología de Valencia, 10.

- 1975: «La cerámica gris monocroma. Puntualizaciones para su estudio». Papeles del Laboratorio de Arqueología de Valencia, 11.

ARANEGUI, C. y GIL MASCARELL, M. 1978: «Vasos plásticos y cerámica con decoración en relieve de barniz negro». Archéologie en Languedoc, 1.

ARIAS, P. E. 1963: Storia della ceramica di età arcaica, classica ed ellenistica e della pittura di età arcaica e classica. Enciclopedia Classica, V.

BALLAND, A. 1969: Céramique étrusco-campanienne à vernis noir. París.

BELTRAN LLORIS, M. 1975: Cerámica romana. Zaragoza.

BLANCO FREIJEIRO, A. 1981: Historia del arte hispánico, I. La Antigüedad, 2. Madrid.

BLAZQUEZ, J. M. 1977: «La interpretación de la pátera de Tivissa». Imagen y Mito. Madrid.

BLECH, M; CAMPS, J. y VALLESPIR, A. 1978: «Eine Reliefschale aus Mallorca». Madrider Mitteilungen, 19.

CORZO SANCHEZ, R. 1975: Osuna. De Pompeyo a César. Sevilla.

CUADRADO, E. 1972: «Tipología de la cerámica ibérica fina de El Cigarralejo, Mula (Murcia)». Trabajos de Prehistoria, 29.

- 1977-78: «Ungüentarios cerámicos en el mundo ibérico. Aportaciones cronológicas». Archivo Español de Arqueología, 50-51.

DOMERGUE, C. 1969: «Céramique de Cales dans les antiques mines d'argent de Carthagène». Archivo Español de Arqueología, 42, 1969.

FABRICOTTI, E. 1980: «Scavi in località Fontana Bona, 1972». Notizia degli Scavi, 33.

FLETCHER, D. y MATA, C. 1981: «Aportación al conocimiento de los ponderales ibéricos». Saguntum, 16.

FORTI, L. 1962: «Gli unguentari del primo periodo ellenistico». Rendiconti della Accademia di Napoli, 37. GALliAZO, M. 1979: Bronzi romani del Museo Civico di Treviso, Roma, 1979.

GARCIA Y BELLIDO, A. 1952: «Cerámica calena en España». Archivo Español de Arqueología, 25.

- 1980: Arte ibérico. Madrid.

GIL MASCARELL, M. 1975: «Sobre las cuevas ibéricas del País Valenciano. Materiales y problemas». Papeles del Laboratorio de Arqueología de Valencia, 11.

GUSI GENER, F. 1974: «Una pátera italiota con medallón en relieve». Cuadernos de Prehistoria y Arqueología de Castellón, 1.

JENTEL, O. 1968: Corpus Vasorum Antiquorum. Musée du Louvre, fasc. 15. París.

1976: Les gutti et les askoi à relief etrusques et apuliens. Essai de classification et de typologie. Leiden.

JOHANNOWSKY, W. 1961: «Relazione preliminari sugli scavi di Cales». Bollettino di Arte, 46.

LAFUENTE VIDAL, J. 1959: Museo Arqueológico Provincial de Alicante. Catálogo-guía. Alicante. 
LEON ALONSO, M. P. 1979: «Plástica ibérica e iberorromana». La Baja Epoca de la cultura ibérica. Madrid.

LUZON, J. M. 1973: Excavaciones en Itálica. Estratigrafía en el Pajar de Artillo. Madrid.

LLOBREGAT, E. 1972: Contestania Ibérica. Alicante.

MINGAZZINI, P. 1958: «Tre brevi note di ceramica ellenistica: l'officina di Lucio Canoleio Caleno». $A r$ cheologia Classica, 10.

MOLINA, M. 1981: «Instrumental médico de la época romana en el Museo Arqueológico Nacional (Madrid)». Archivo Español de Arqueología, 54.

MONTAGNA PASQUINUCCI, M. 1972: «La ceramica a vernice nera di Volterra». Mélanges de l'Ecole Française de Rome. Antiquité, 84.

MOREL, J. P..1965: La céramique a vernis noir du Forum Romain et du Palatine. París.

- 1978: «A propos des céramiques campaniennes de France et d'Espagne». Archéologie en Languedoc, 1.

- 1980: «La céramique campanienne: acquis et problémes». Céramiques hellénistiques et romaines. París.

- 1981: Céramique campanienne: les formes. París.

NORDSTRÖM, S. 1961: Los cartagineses en la costa alicantina. Alicante.

- 1969: La céramique peinte ibérique de la province d'Alicante. Alicante.

OLMOS, R. 1982: Estudios de iconografía, I. Madrid.

PAGENSTECHER, R. 1909: Die calenische Reliefkeramik. Berlín.

RADDATZ, K. 1969: Die Schatzfunde der Iberischen Halbinsel. Berlín.

RAMOS FERNANDEZ, R. 1982: «Precisiones para la clasificación de la cerámica ibérica». Lucentum, I.

RICHTER, G. M. 1941: «A Greek Silver Phiale in the Metropolitan Museum». American Journal of Archaeology, 45.

RIPOLL, E. y BARBERA, J. 1968: «Dos fragmentos de cerámica con medallón en relieve del poblado ibérico de «La Massana» cerca de Vilafranca del Penedés (Barcelona)». Rivista di Studi Liguri, 34 (Ommaggio a F. Benoit, II).

RIPOLLES, P. P. 1982: La circulación monetaria en la Tarraconense mediterránea. Tesis doctoral inédita. Valencia.

RIZZO, G. E., 1946: Monete greche della Sicilia. Roma.

ROBINSON, D. 1941: Excavations at Olynthus, X. Baltimore.

ROCCO, E. 1959: «Caleni Vasi». Enciclopedia dell'Arte Antica, II. Roma.

SANESI, L. 1976: «Frammenti inediti di ceramica calena». Rendiconti della Accademia di Napoli, 51.

- 1978: «Sulla firma di un ceramista caleno e sulla questione dei vici». Parola del Pasato, 33.

SANMARTI, E. 1978: Las cerámicas campanienses de Emporion y Rhode. Barcelona.

- 1978 b: «L'atelier des pateres à trois palmetes radiales et quelques productions connexes», Archéologie en Languedoc, 1.

SERRA RAFOLS, J. de C. 1941: «El poblado ibérico del Castellet de Banyoles (Tivissa, Bajo Ebro)». Ampurias, 3.

- 1964-65: «La destrucción del poblado ibérico del Castellet de Banyoles de Tivissa (Bajo Ebro)». Ampurias, 26-27.

SHEFTON, B. B. 1971: "Persian Gold and Attic Black of the 5th. and 4th. Centuries b. C.». Annales Archéologiques Arabes Syriennes, 12.

SPARKES, B. y TALCOTT, L. 1970: The Athenian Agora, XII. Black and Plain Pottery of the 6th., 5th. and 4th. Centuries $b$. C. Princeton.

STRONG, D. E. 1966: Greek and Roman Gold and Silver. London.

TARRADELL, M. 1970: «Nuevo plomo greco-ibérico de La Serreta de Alcoy (Campaña 1968)». Actas del XI Congreso Nacional de Arqueología. Zaragoza.

THOMSON, E. 1934: «Two Centuries of Hellenistic Pottery». Hesperia, 3. 